\title{
Change In The Variability In The Western Pacific Pattern During Boreal Winter: Roles of Tropical Pacific Sea Surface Temperature Anomalies And North Pacific Storm Track Activity
}

\section{Hasi Aru}

Institute of Atmospheric Physics Chinese Academy of Sciences

\section{Shangfeng Chen}

Institute of Atmospheric Physics Chinese Academy of Sciences

Wen Chen ( $\nabla$ chenw@mail.iap.ac.cn )

Institute of Atmospheric Physics Chinese Academy of Sciences https://orcid.org/0000-0001-93279079

\section{Research Article}

Keywords: Western Pacific pattern, ENSO, Storm track, Interdecadal change

Posted Date: July 13th, 2021

DOI: https://doi.org/10.21203/rs.3.rs-600357/v1

License: (c) (i) This work is licensed under a Creative Commons Attribution 4.0 International License. Read Full License 


\section{Abstract}

Using multiple reanalysis datasets, this study reveals that the variability in the Western Pacific pattern (WP) in boreal winter has shown notable changes during recent decades. The variability in the winter WP exhibited a marked weakening trend before the early 2000 s and increased slightly thereafter. Two epochs with the highest and lowest WP variabilities are selected for a comparative analysis. Winter WP-related meridional dipole atmospheric anomalies over the North Pacific were stronger and had a broader range during the high-variability epoch than during the low-variability epoch. Correspondingly, the winter WP had larger impacts on surface temperature variations over Eurasia and North America during the highvariability epoch than during the low-variability epoch. We find that the shift in the winter WP variability is closely related to changes in the connection between the winter WP and the El Niño-Southern Oscillation (ENSO) and to changes in the amplitude of the North Pacific storm track. Specifically, ENSO had a closer connection with the WP during the high-variability epoch, at which time the amplitude of the North Pacific storm track was also stronger. During the high-variability epoch, the extratropical atmospheric anomalies generated by the tropical ENSO shifted westward and projected more on the WP-related atmospheric anomalies, thus contributing to an increase in WP variability. In addition, the larger amplitude of the North Pacific storm track that occurred during the high-variability epoch led to the stronger feedback of synoptic-scale eddies to the mean flow and contributed to stronger WP variability. Further analysis indicates that the change in the connection of ENSO with the WP may be partly related to the zonal shift of the sea surface temperature anomaly in the tropical Pacific associated with ENSO.

\section{Introduction}

The western Pacific pattern (WP), one of the most prominent teleconnections in the Northern Hemisphere, features a marked north-south seesaw pattern in 500-hPa geopotential height anomalies over the Far East and western North Pacific (Wallace and Gutzler 1981; Mo and Livezey 1986; Barnston and Livezey 1987). A growing body of literature highlights the distinct impacts of the WP on weather and climate anomalies in Eurasia and North America. For example, studies have indicated that the WP exerts pronounced impacts on the East Asian winter monsoon, the occurrence frequency of the East Asian cold surge, and surface air temperature (SAT) anomalies over East Asia and North America (e.g., Takaya and Nakamura 2005a, b; Linkin and Nigam 2008; Takaya and Nakamura 2013; Wang and Chen 2014; Chen and Song 2018; Aru et al. 2021). In addition, several studies have reported that the WP has a notable modulating effect on the connection between the Arctic Oscillation (AO) and SAT anomalies over East Asia (Cheung et al., 2016; Oh et al., 2017; Lim and Kim, 2013). In particular, the spatial distributions and amplitudes of AO-generated winter SAT anomalies over East Asia strongly depend on the phase of the WP (Park and Ahn 2016; Oh et al., 2017). Studies have argued that the WP-induced SAT anomalies over East Asia and North America are comparable to, or are even stronger than, those associated with the El Niño-Southern Oscillation (ENSO) and the Pacific-North American teleconnection pattern (Cheung et al., 2016; Oh et al., 2017; Lim and Kim, 2013). Furthermore, variability in the WP has a marked effect on the jet stream over the North Pacific (Wettstein and Wallace 2010; Tanaka et al. 2016; Ma and Zhang 2018), as well as on sea ice conditions in the Arctic Ocean, especially in the Bering and Okhotsk Seas (Linkin and 
Nigam 2008; Yuan et al. 2015). Due to the crucial impact of the WP, investigating the factors responsible for WP variability is of great importance.

There are two main lines of thought concerning the mechanisms of the formation and maintenance of the WP. On the one hand, it is generally accepted that the WP is an intrinsic atmospheric mode that can form and sustain itself in the absence of external forcing. Studies have demonstrated that the interaction between storm tracks (i.e., synoptic-scale eddies) and mean flows, as well as the associated feedback of synoptic-scale eddies, are the essential mechanisms of the formation and maintenance of the WP (Hsu and Wallace 1985; Nakamura et al. 1987; Lau 1988; Lau and Nath 1991; Wettstein and Wallace 2010; Athanasiadis et al. 2010; Li and Wettstein 2012). Rivière (2010) highlighted a dynamic link between Rossby wave breaking and the WP that hinges on the latitudinal fluctuations of the Pacific jet stream. In addition, studies have indicated that the extraction of kinetic and available potential energy from the basic flow via barotropic and baroclinic energy conversion processes plays a crucial role in the maintenance of the WP (Tanaka et al. 2016; Sung et al. 2019, 2020).

On the other hand, studies have argued that external forcings (such as tropical sea surface temperatures (SSTs), Eurasian snow cover, and Arctic sea ice anomalies) also play a role in the excitation and maintenance of the WP (Horel and Wallace 1981; Kodera 1998; Koide and Kodera 1999; Linkin and Nigam 2008; Hirose et al. 2009; Frankignoul et al. 2011; Oshika et al. 2014; Nakamura et al. 2015). Horel and Wallace (1981) revealed that SST anomalies in the tropical Pacific related to ENSO contributed to the formation of the WP via a heating-induced atmospheric Rossby wave train. Kodera (1998) also claimed that a link exists between the WP and the upstream circulation conditions over the Eurasian continent during early winter. Evidence suggests that the Arctic sea ice anomalies generated by the North Atlantic Oscillation in the preceding winter could induce a WP-like atmospheric anomaly pattern in the following winter (Nakamura et al. 2015). Kodera (1998) argued that snow cover over Siberia can affect the WP by modulating the WP-ENSO connection. Some studies have argued that the relationships between the WP and these external forcings are unstable (Furtado et al. 2012; Park et al. 2018; Xu and Fan 2020).

As highlighted above, many studies have investigated the interannual variability in the WP as well as the impacts of the WP on climate anomalies over Eurasia and North America. At present, few studies have discussed whether the historical variabilities (i.e., amplitude) in the WP are stable. The impacts of the WP on climatic anomalies may depend strongly on the amplitude of the WP. For example, recent studies have indicated that an extremely strong winter WP event was the largest contributor to the occurrence of record-breaking cold events over North America during the winter of 2013/14 (Yu and Zhang 2015; Baxter and Nigam 2015; Lee et al. 2015). Cheung et al. (2015) reported that a WP-like pattern notably accounted for the persistent cold spells that occurred in Hong Kong over 1948/49-2013/14. In addition, Sung et al. (2019) argued that changes in climate extremes over North America are attributable to changes in WP variations. Hence, it is critical to examine interdecadal changes in the historical variability in the WP, as these changes have important implications for the prediction and projection of mean and extreme climate conditions over Eurasia and North America. 
The remainder of this study is structured as follows. Section 2 describes the data and methods. Section 3 examines the interdecadal changes in variability in the WP. In addition, in this section, we compare atmospheric and surface air temperature anomalies associated with the winter WP before and after the interdecadal changes occurred. Section 4 examines the factors responsible for changes in WP variability. The summary and discussion are shown in Sect. 5.

\section{Data And Methods}

\section{a. Data}

Monthly and daily geopotential height and horizontal wind data were extracted from the National Centers for Environmental Prediction (NCEP) - National Center for Atmospheric Research (NCAR) reanalysis dataset (Kalnay et al. 1996). The NCEP-NCAR reanalysis dataset is available from 1948 to the present with atmospheric variables at various pressure levels gridded at a $2.5^{\circ} \times 2.5^{\circ}$ horizontal resolution. For a cross-check, we also compared the results obtained from other datasets, including atmospheric data with a horizontal resolution of $1.0^{\circ} \times 1.0^{\circ}$ spanning the period from January 1979 to August 2019 provided by the European Centre for Medium-Range Weather Forecasts Interim (ERA-Interim) reanalysis product (Dee et al. 2011) and atmospheric data with a horizontal resolution of $1.25^{\circ} \times 1.25^{\circ}$ produced by the second Japanese global atmospheric reanalysis project (JRA55) (Kobayashi et al. 2015) from January 1958 to the present.

Monthly mean surface air temperature data were collected from the University of Delaware (Willmott and Matsuura 2001) with a horizontal resolution of $0.5^{\circ} \times 0.5^{\circ}$ and availability from January 1900 to December 2017. The monthly SST data used in this study were derived from the National Oceanic and Atmospheric Administration (NOAA) Extended Reconstructed SST version 5 (ERSST.v5) dataset (Huang et al. 2017). This dataset covers the period from January 1854 to the present and has a $2^{\circ} \times 2^{\circ}$ horizontal resolution. The datasets employed in this study are summarized in Table 1.

Table 1

List of the observational and reanalysis datasets used in this study.

\begin{tabular}{|llll|}
\hline Dataset & Variance & \multicolumn{1}{c}{ Reference } & Data period \\
\hline $\begin{array}{l}\text { NCEP- } \\
\text { NCAR }\end{array}$ & $\begin{array}{l}\text { Monthly and daily geopotential height, } \\
\text { winds }\end{array}$ & Kalnay et al. (1996) & $\begin{array}{l}1948 \text { to } \\
\text { present }\end{array}$ \\
\hline JRA55 & Monthly geopotential height & $\begin{array}{l}\text { Kobayashi et al. } \\
(2015)\end{array}$ & $\begin{array}{l}1958 \text { to } \\
\text { present }\end{array}$ \\
\hline $\begin{array}{l}\text { ERA- } \\
\text { Interim }\end{array}$ & Monthly geopotential height & Dee et al. (2011) & 1979 to 2019 \\
\hline ERSSTv5 & Monthly SST & Huang et al. (2017) & $\begin{array}{l}1854 \text { to } \\
\text { present }\end{array}$ \\
\hline
\end{tabular}

b. Identification of the employed indices 
Following previous studies (Nishii et al. 2010; Aru et al. 2021), the WP pattern is described by the first empirical orthogonal function mode (EOF1) of the 500-hPa geopotential height anomalies (Z500) over the western North Pacific region $\left(20^{\circ} \mathrm{N}-70^{\circ} \mathrm{N}, 120^{\circ} \mathrm{E}-180^{\circ}\right)$. The principal component (PC) time series corresponding to EOF1 is considered the WP index. Notably, the geopotential height anomalies were weighted by the square root of the cosine latitude prior to the EOF analysis to account for area differences occurring at different latitudes (Thompson and Wallace 2000). As indicated in previous studies, storm tracks can be highlighted by various eddy variance and covariance quantities (Blackmon et al. 1977; Chang and Fu 2002; Wettstein and Wallace 2010). In this study, the storm track activity (STA) is described based on the 2-8-day bandpass-filtered 500-hPa geopotential height variance (referred to as

$\overline{Z^{\prime} Z^{\prime}} 500$, where the apostrophe indicates the filtering anomalies and the overbar denotes the winter mean). Following previous studies (Chen et al. 2014; Zhao et al. 2019, 2020; Piao et al. 2020), the Niño3.4 SST index was used to characterize the ENSO variability; this index is defined as the area-average SST over the area comprising $5^{\circ} \mathrm{S}-5^{\circ} \mathrm{N}$ and $170^{\circ}-120^{\circ} \mathrm{W}$.

The analysis period spanned from 1949 to 2019, including seventy-one winters. Winter is considered the average of December, January, and February (DJF). Here, the winter of 1949 refers to December in 1948 and January and February in 1949. The interannual variations in all variables were obtained by subjecting the original variables to a 9-yr high-pass Lanczos filter (Duchon 1979). Significant composite difference, correlation and regression coefficient levels were estimated based on two-tailed Student's $t$-tests. A twotailed F-test was applied to test the significance levels of the differences between two standard deviations.

\section{c. Geopotential height tendency}

The geopotential height tendency is used to quantitatively describe the feedback of synoptic-scale eddies to low-frequency flows (Lau and Holopainen 1984; Lau 1988; Cai et al. 2007; Chen et al. 2015, 2020a, 2020b; Hu et al. 2021) and can be expressed as follows:

$F=\frac{f}{g} \nabla^{-2}\left[-\nabla \cdot \overline{\left(V^{\prime} \zeta^{\prime}\right)}\right]$

where $g$ is the acceleration of gravity, $f$ denotes the Coriolis parameter, and $V^{\prime}$ and $\zeta^{\prime}$ correspond to the synoptic-scale winds and vorticity, respectively. Moreover, $\zeta^{\prime}$ is calculated according to synoptic-scale winds. Synoptic-scale variations are obtained by subjecting the daily mean data to a 2-8-day bandpass Lanczos filter (Duchon 1979).

\section{Interdecadal Variations In The Winter Wp Variability}

\section{a. Temporal variation features}

Before investigating the changes in WP variability, we first examined the spatiotemporal features of the WP during boreal winter based on the NCEP-NCAR reanalysis data over the 1949-2019 period. Here, the 
spatial pattern of the WP was represented by the EOF1 of the Z500 anomalies over $20^{\circ} \mathrm{N}-70^{\circ} \mathrm{N}$ and $120^{\circ} \mathrm{E}-$ $180^{\circ}$. The EOF1 of the Z500 anomalies in boreal winter over $1949-2019$ accounted for $44.3 \%$ of the total variance. Figure 1a depicts a map of Z500 anomalies regressed onto the winter WP index. The spatial pattern of the WP features a meridional seesaw pattern in the Z 500 anomalies between the subtropics and mid-latitudes of the western North Pacific (WNP) (Fig. 1a). Concurrent with the dipole atmospheric anomaly pattern over the WNP, marked positive Z500 anomalies were observed north of the North American Great Lakes (Fig. 1a). In addition, large-scale positive Z500 anomalies appeared in the tropics, suggesting a connection of the WP with tropical SST anomalies, which was later investigated.

We also examined the WP based on the JRA55 and ERA-interim reanalysis datasets. The winter WP indices derived from the three reanalysis datasets were highly correlated with each other during the overlapping period (Fig. 1b). The correlation coefficient between the WP indices obtained from the JRA55 (ERA-interim) and NCEP-NCAR datasets over 1959-2019 (1979-2019) reached 0.94 (0.89), which was significant at the $99.9 \%$ confidence level. In addition, Fig. $1 \mathrm{~b}$ shows that the amplitude of the winter WP index seems to be larger before the early 1980s than after. Figure 2 confirms the 25 -yr moving standard deviations of the winter WP index. The years shown in Fig. 2 represent the central year of the $25-\mathrm{yr}$ moving window. From Fig. 2, we can pinpoint a considerable weakening of WP variability lasting from the early 1960 s to the late 1990 s (Fig. 2). After the early 2010 s, WP variability showed a slightly increasing trend (Fig. 2). The results obtained from the NCEP-NCAR (Fig. 2a) and JRA55 (Fig. 2b) datasets are similar (Fig. 2). In the following text, we only present the results derived from the NCEP-NCAR dataset. The above analysis indicates that the winter WP variability exhibited notable changes in the past. To help understand the characteristics and factors associated with these interdecadal changes in WP variability, we selected the two 25-yr epochs with the highest and lowest WP variabilities for a subsequent comparative analysis. The standard deviation of the winter WP was highest during 1950-1974 (corresponding to the central year of 1962) and lowest from 1989-2013 (corresponding to the central year of 2001). In particular, the standard deviation of the winter WP index during 1950-1974 was 1.12, which is approximately two times greater than that during 1989-2013 (0.66). Notably, the difference in the standard deviations of the winter WP index between 1950-1974 and 1989-2013 was significant at the $95 \%$ confidence level according to a two-tailed F-test. Hence, 1950-1974 and 1989-2013 were selected to represent high and low epochs of WP variability in the comparative analysis.

\section{b. Changes in atmospheric and SAT anomalies related to the WP}

In this subsection, we first compare the differences in the spatial structure of the WP between 1950-1974 and 1989-2013. Then, we examine the WP-related SAT anomalies during the two periods. Figure 3 shows the composite atmospheric circulation anomalies between the positive and negative phases of the winter WP index during the two studied epochs. The positive and negative phases of the winter WP index were identified according to the application of \pm 0.5 standard deviations (Table 2). During both epochs, the positive phase of the WP was associated with a significant increase in zonal winds over the North Pacific at approximately $40^{\circ} \mathrm{N}-55^{\circ} \mathrm{N}$, indicative of a northward shift of the eddy-driven jet stream over the northwestern Pacific (Figs. 3a and 3b); this result is consistent with the findings of Li and Wettstein 
(2012) and Wettstein and Wallace (2010). In addition, significant decreases in 200-hPa zonal winds were observed around the Russian Far East with an eastward extension to Alaska (Figs. 3a and 3d). In comparison, the zonal wind anomalies over the North Pacific related to the winter WP index covered larger areas and extended farther westward during 1950-1974 than during 1989-2013. In addition, significant decreases in the 200-hPa zonal wind also occurred to the south of Japan, in the tropical eastern Pacific and in the Great Lakes region during 1950-1974 that could not be observed during 1989-2013. The composited 500-hPa geopotential height anomalies during 1950-1974 exhibited a northwest-southeastoriented dipole pattern that stretched zonally over the subtropics and mid-and high latitudes of the North Pacific (Fig. 3b). During 1989-2013, a marked dipole pattern also appeared over the western North Pacific, but its intensity was weaker and its latitudinal extension was smaller than that of its counterpart during 1950-1974 (Fig. 3e). In addition, prominent dipole sea level pressure (SLP) and 850-hPa atmospheric anomaly patterns occurred over the western Pacific in the two epochs (Figs. 3c, f), with much stronger amplitudes in the earlier epoch. The above results indicate that larger WP variability tends to correspond to stronger atmospheric anomaly amplitudes over the North Pacific.

Table 2

List of the positive and negative years of the 9-yr high-pass-filtered PC1 time series (defined as the WP index) pertinent to the EOF1 of 500-hPa geopotential height anomalies over the western North Pacific during 1949-2019. The positive and negative cases are selected as the years in which the absolute normalized values of the PC time series are larger than 0.5 .

\begin{tabular}{|lll|}
\hline & $1950-1974$ & $1989-2013$ \\
\hline $\begin{array}{l}\text { Positive } \\
\text { WPs }\end{array}$ & $\begin{array}{l}1952,1954,1958,1959,1960,1964,1966,1967, \\
1969,1973\end{array}$ & $\begin{array}{l}1989,1992,1998,1999,2007, \\
2012,2013\end{array}$ \\
\hline $\begin{array}{l}\text { Negative } \\
\text { WPs }\end{array}$ & $\begin{array}{l}1950,1956,1957,1962,1963,1965,1968,1971, \\
1974\end{array}$ & $1991,1997,2000,2005,2011$ \\
\hline
\end{tabular}

Studies have demonstrated that WP-related atmospheric anomalies significantly impact SAT variations over Eurasia and North America by modulating atmospheric anomalies (Linkin and Nigam 2008; Lim and Kim 2013; Takaya and Nakamura 2013; Yu and Zhang 2015; Baxter and Nigam 2015; Shi et al. 2019). In the following text, we further examine differences in the WP-related SAT anomalies recorded between the 1950-1974 and 1989-2013 periods. Figures $4 \mathrm{a}$ and $4 \mathrm{~b}$ display composited wintertime SAT anomalies between the positive and negative phases of the winter WP index during the two studied epochs, respectively. During 1950-1974, significant decreases in the SAT occurred around the Russian Far East; these decreases were attributed to the northerly wind anomalies in this region (Fig. 4a). Under these conditions, anomalous northerly winds brought colder air from higher latitudes, leading to SAT cooling (Fig. 4a). The SATs in northern Mexico and southeastern America also presented significant decreases in this period. In addition, significant SAT warming was seen over central Canada and many parts of south and southeast Asia (Fig. 4a). Marked increases in SAT also appeared over the northern part of South America and a small patch of Alaska (Fig. 4a). Conversely, during 1989-2013, the composited SAT anomalies associated with the WP were not evident (Fig. 4b). These differences in WP-related SAT anomalies may have been partially related to differences in WP-related atmospheric anomalies. In 
particular, the atmospheric anomalies over the North Pacific were stronger and covered larger areas during 1950-1974 than during 1989-2013. This feature explains the stronger impact of the winter WP on the SAT anomalies during 1950-1974 than during 1989-2013.

\section{Factors Affecting The Interdecadal Variations In The Winter Wp}

In this section, we examine the factors affecting the changes in WP variability. We first examine the role of tropical Pacific SST anomalies. Then, we discuss the role of North Pacific storm track activity.

\section{a. Role of tropical Pacific SST anomalies}

Studies have suggested that the tropical SST anomalies that are related to ENSO significantly contribute to WP variability by triggering an extratropical atmospheric teleconnection (Horel and Wallace 1981; Barnston and Livezey 1987; Koide and Kodera 1999; Wang et al. 2007; Furtado et al. 2012; He et al. 2013; Park et al. 2018; Aru et al. 2021). Figure 5 presents the lead-lag correlation coefficients of the wintertime WP index $(D(-1) J F(0))$ with the Niño3.4 index from the preceding summer (JJA(-1)) to the following summer $(\mathrm{JJA}(0))$. Here, the time notations " 1 " and "0" denote the order of the years. A remarkable difference was found in the WP-ENSO correlation between the two epochs (Fig. 5). During 1950-1974, the wintertime WP index had a significant positive correlation with the Niño3.4 index from the previous summer (JJA(-1)) to the following spring (MAM(0)). In contrast, the correlation of the winter WP index with the Niño3.4 index was weak during the 1989-2013 period. Hence, ENSO has a strong (weak) relationship with the WP during periods of strong (weak) WP variability. The above results imply that the observed changes in WP variability may be partly related to changes in the ENSO-WP relation.

To confirm the above speculation, we examined the 25-yr moving standard deviations of the winter WP index and the 25-yr running correlation coefficients of the winter WP index with the Niño3.4 index (Fig. 6a). As is clear in Fig. 6a, the changes in the winter WP-ENSO relation have very good agreement with the changes in WP variability. Figure $6 \mathrm{~b}$ presents a scatter plot of the $25-\mathrm{yr}$ moving standard deviations of the winter WP index versus the 25-yr running correlations of the winter WP index with the Niño3.4 index. The two quantities shown in Fig. 6b are highly correlated with each other, with correlation coefficients as high as 0.94 . Therefore, the above evidence indicates that changes in the WP-ENSO relationship are closely related to variations in WP variability. Specifically, during period with strong (weak) WP-ENSO connections, the variability in the WP is strong (weak).

Figure 7 depicts maps of the atmospheric and SST anomalies in winter regressed onto the simultaneously calculated winter Niño3.4 index during 1950-1974 and 1989-2013. During 1950-1974, the geopotential height anomalies in the upper troposphere $(200 \mathrm{hPa})$ featured marked negative anomalies over the Russian Far East extending eastward to the west of Alaska, accompanied by largescale positive anomalies over the tropics (Fig. 7a). The Z500, 850-hPa wind and SLP anomalies (Figs. 7b7c) were similar in this period to those related to the WP (Fig. 1a), with positive Z500, SLP and anticyclonic anomalies observed over the subtropical WNP and anomalies with opposite signs observed over the mid-high-latitude WNP. Hence, during this period, the ENSO-related SST anomalies in the tropics 
strongly impacted the WP and thus contributed to stronger WP variability. The atmospheric anomalies related to the Niño3.4 index over the North Pacific that occurred during 1989-2013 (Figs. 7e-g) show notable differences from those recorded during 1950-1974 (Figs. 7a-c). In particular, the atmospheric anomalies related to the Niño3.4 index exhibited a PNA-like pattern, with strong negative geopotential height, SLP and cyclonic anomalies over the mid-latitude North Pacific and the southeastern United States, along with anomalies with opposite signs over the subtropical northeastern Pacific and northern Canada (Figs. 7e-g). The above evidence indicates that the atmospheric anomalies generated by tropical ENSO projected more onto the PNA pattern during 1989-2013, in sharp contrast to the WP pattern during 1950-1974. Therefore, the weak contribution of the tropical SST anomalies related to ENSO to the WP may partly explain the weak WP variability recorded during 1989-2013.

The above evidence indicates that ENSO-related atmospheric anomalies showed notable differences between the two periods. A question naturally arose: what leads to changes in the spatial structure of atmospheric anomalies that are related to ENSO? Figs. $7 \mathrm{~d}$ and $7 \mathrm{~h}$ depict the regression patterns of winter SST anomalies upon the winter Niño3.4 index. The spatial patterns of the SST anomalies in the tropics appeared similar during the two periods, with significant SST warming occurring in the tropical central and eastern Pacific and in the tropical Indian Ocean, accompanied by SST cooling in the tropical western Pacific. In addition, the amplitudes of the SST anomalies in the tropical central and eastern Pacific were similar between the two periods. In particular, we examined a scatter plot between the 25-yr running correlations of the winter WP index and Niño3.4 index against the 25-yr running standard deviations of the Niño3.4 index (not shown). The correlation coefficient between the above two variables was weak, indicating that a change in the ENSO intensity could not explain changes in the spatial structure of ENSOinduced extratropical atmospheric anomalies and thus could not explain changes in the ENSO-WP relation.

Studies have demonstrated that the spatial distributions of atmospheric anomalies induced by tropical SST anomalies are highly sensitive to the zonal locations of SST anomalies in the tropics (Trenberth et al. 1998; Hoerling and Kumar 2002; Barsugli and Sardeshmukh 2002; Zhou et al. 2014; Jo et al. 2015; Soulard et al. 2019; Chen et al. 2021). In particular, the ENSO-induced atmospheric anomalies over the North Pacific shifted eastward (westward) when the ENSO-related SST anomalies in the tropical Pacific were located farther eastward (westward) (Jo et al. 2015; Soulard et al. 2019; Chen et al. 2021). Following Chen et al. (2021), a quantification of the zonal shift of the ENSO-related SST anomalies in the tropics was defined as the longitude of the $0^{\circ} \mathrm{C}$ isotherms of the SST anomalies in the equatorial western Pacific. For accuracy, we interpolated the SST data onto a higher-resolution grid of $0.5^{\circ} \times 0.5^{\circ}$, taking the mean longitude of the $0^{\circ} \mathrm{C}$ isotherms between $5^{\circ} \mathrm{S}$ and $5^{\circ} \mathrm{N}$ as the index describing the east-west movement of the ENSO-related SST anomaly pattern, termed the "zero line". Figure 8a presents a scatter plot of the zero line of SST anomalies in the tropical Pacific versus the 25-yr moving standard deviations of the WP index. Figure $8 \mathrm{~b}$ shows a scatter plot of the zero line versus the 25-yr running correlation of the winter WP index with the Niño3.4 index. The correlation coefficients between the two quantities shown in Fig. $8 \mathrm{a}$ and Fig. $8 b$ were -0.50 and -0.38 , respectively, both of which are significant at the $99 \%$ confidence level according to two-tailed Student's $t$ test. These results suggest that changes in the zonal location of 
tropical SST anomalies related to ENSO may partly contribute to changes in the spatial structure of the atmospheric anomalies induced by ENSO; this result is consistent with previous findings (Jo et al. 2015; Soulard et al. 2019; Chen et al. 2021).

\section{b. Impact of ENSO on the WP variability in a Coupled Model Simulation}

The above analyses indicate that the observed changes in the variability in the WP were partly attributed to changes in the ENSO-WP relationship. In this subsection, we use a long historical simulation of a coupled climate model over 1850-2014 to confirm this conclusion. This long simulation was conducted using the National Aeronautics and Space Administration (NASA) Goddard Institute for Space Studies (GISS) climate model GISS-E2.1-G, which is participating in CMIP6 (Kelley et al. 2020). A more comprehensive description of GISS-E2.1-G can be found in Kelley et al. (2020). The atmospheric variables obtained from the GISS-E2.1-G historical simulation were interpolated to a common horizontal resolution of $2.5^{\circ} \times 2.5^{\circ}$ to facilitate comparisons with the observations. The WP index in GISS-E2.1-G was obtained by projecting the model-simulated Z500 anomalies onto the observed EOF1 loading pattern.

We first examined the ability of the GISS-E2.1-G model to simulate the spatial patterns of the WP and ENSO. Figure $9 \mathrm{a}$ displays the winter $500-\mathrm{hPa}$ geopotential height anomalies obtained by regression on the normalized WP index for the 1850-2014 period. This figure depicts a canonical meridional dipole pattern over the subtropical western North Pacific and mid- to high-latitude North Pacific and the Far East, bearing a close resemblance to the WP shown in the observations (Fig. 1a). In addition, ENSO-related SST anomalies are simulated well by the model, featuring prominent SST warming in the tropical central and eastern Pacific and Indian Ocean, together with SST cooling in the tropical western Pacific (Fig. 9b). Moreover, the GISS-E2.1-G model simulated the spatial distribution of the WP-related SAT anomalies over Eurasia and the North Pacific well, as has been reported in previous studies (Sung et al. 2019, 2020; Aru et al. 2021). Hence, it is reasonable to use the GISS-E2.1-G model to examine changes in the variability in the WP and changes in the WP-ENSO relation.

Figure 10a shows the 25-yr moving standard deviations of the WP index and the 25-yr running correlation coefficients between the winter WP index and Niño3.4 index obtained with the GISS-E2.1-G model. The change in the variability in the wintertime WP corresponded well with the variation in the WP-ENSO relation, except during the early 20th century (Fig. 10a). The correlation coefficient between the time series of the 25-yr moving standard deviation of the WP index and the 25-yr running correlation of the WP index with the Niño3.4 index reached 0.62, which was significant at the $99 \%$ confidence level (Fig. 10b). Hence, the GISS-E2.1-G-derived long-term simulations further confirmed that changes in the winter WP variability are closely related to changes in the ENSO-WP relation. In addition, a statistically significant correlation coefficient of 0.35 was found between the variation in the WP-ENSO relation and the variation in the zero line of the ENSO-related SST anomalies in the tropical Pacific (Fig. 10c). This finding confirmed the observed results in which changes in the wintertime WP-ENSO relation were determined to be partly related to the zonal shifts of ENSO-related SST anomalies in the tropics. 
Apart from tropical SSTs, studies have suggested that the interaction between the low-frequency mean flow and synoptic-scale eddies is a crucial factor affecting the formation and maintenance of atmospheric circulation patterns associated with the WP (Lau 1988; Chang and Fu 2002; Linkin and Nigam 2008; Tanaka et al. 2016; Wettstein and Wallace 2010). This, therefore, suggests that changes in the wave-mean flow interactions and associated synoptic-scale eddy feedbacks may also contribute to changes in the WP variability. Figures $11 \mathrm{a}$ and $11 \mathrm{c}$ show regression maps of storm track anomalies against the winter WP index for the 1950-1974 and 1989-2013 periods, respectively. During 1950-1974, marked increases in storm track activity occurred in the area of approximately $40^{\circ}-60^{\circ} \mathrm{N}$ over the North Pacific (Fig. 11a), corresponding well with westerly anomalies in the same region (Fig. 3c). Studies have demonstrated that increased (decreased) storm track activity is associated with westerly (easterly) anomalies and is immediately accompanied by positive anticyclonic vorticity forcing to the south and cyclonic vorticity forcing to the north (Lau et al. 1988; Chen et al. 2014), helping maintain a WP-like meridional atmospheric dipole pattern (Fig. 3c). Positive storm track anomalies were also observed over the North Pacific during 1989-2013, but these anomalies were less statistically significant (Fig. 11c). We further calculated the geopotential height tendency to quantitatively examine changes in the feedback of the synoptic-scale eddy to the mean flow (e.g., Lau and Holopainen 1984; Lau 1988; Cai et al. 2007). Figures $11 \mathrm{~b}$ and $11 \mathrm{~d}$ show the regression maps of geopotential height tendency at $500 \mathrm{hPa}$ onto the winter WP index during the two studied periods. During 1950-1974, the spatial structure of the geopotential height tendency anomalies (Fig. 11b) was similar to those of the atmospheric anomalies related to the WP index (Fig. 3b). In particular, notable negative geopotential height tendency anomalies occurred over the Russian Far East, extending eastward to the Aleutian region, and positive geopotential height tendency anomalies were found over East Asia, extending eastward to the central North Pacific (Fig. 11b). Hence, during 1950-1974, the feedback of synoptic eddies to the mean flow was conducive to the formation and maintenance of the WP. During 1989-2013, the geopotential height tendency anomalies also exhibited a meridional dipole pattern over the North Pacific but with much weaker amplitudes and less significance compared to those that occurred during 1950-1974. Hence, a stronger wave-mean flow interaction and stronger feedback of synoptic-scale eddies to the mean flow may also partly contribute to the stronger WP variability that occurred during 1950-1974.

What contributes to changes in the feedback strength of synoptic-scale eddies? Studies have indicated that the feedback strength of synoptic-scale eddies is related to changes in the mean-state circulation and amplitude of storm track activity (Lau 1988; Chang and Fu 2002; Jin et al. 2006a, b; Kug et al. 2009a; Jin 2010). We examined the difference in the mean flow between the 1950-1974 and 1989-2013 periods. The difference was weak over the North Pacific (not shown). This implies that the change in the feedback strength of the synoptic-scale eddies to the mean flow is not related to changes in the meanstate circulation. Then, we further examined the change in the amplitude of the storm track activity. Following previous studies (Lee et al., 2012; Wettstein and Wallace, 2010; Ma and Zhang 2018), we used EOF analysis to obtain the dominant mode of storm track activity over the North Pacific $\left(20^{\circ}-90^{\circ} \mathrm{N}, 120^{\circ} \mathrm{E}-\right.$ $100^{\circ} \mathrm{W}$ ). The long-term trend was removed prior to the EOF analysis. Figure 12a depicts the EOF1 of the winter storm track activity over the North Pacific, and Fig. 12b shows the corresponding PC time series. 
The EOF1 of the North Pacific storm track activity accounted for $19.62 \%$ of the total variance and was characterized by a monopole pattern over the North Pacific. The center of EOF1 corresponded well with the maximum center of the mean winter storm track, as has been reported in previous studies (Lee et al., 2012; Wettstein and Wallace, 2010). This suggests that EOF1 represents variations in the wintertime North Pacific storm track intensity. Thus, the corresponding PC1 time series was used to represent the intensity index of the North Pacific storm track. The variability in the PC1 time series was stronger during 1950-1974 than during 1989-2013, indicating that the amplitude of the North Pacific storm track activity was stronger during 1950-1974 than during 1989-2013, corresponding to the stronger feedback of synoptic-scale eddies to the mean flow measured during the earlier period. Figure 13 shows a scatter plot of the 25-yr moving standard deviations of the North Pacific storm track intensity index against the 25-yr moving standard deviations of the winter WP index. The correlation coefficient between the two variables shown in Fig. 12 reached 0.69, which was significant at the $99.9 \%$ confidence level. This result indicates that changes in the intensity of the North Pacific storm track also play a role in modulating changes in the WP intensity.

\section{Conclusion And Discussion}

This study investigates changes in the variability in the wintertime WP. We found that the variability in the WP showed a significantly weakening trend from the 1950 s to the late 2000 s. After the early 2000 s, the variability in the WP exhibited a slightly increasing trend. The two epochs with the strongest and weakest WP variabilities were selected for a comparative analysis. Figure 14 summarizes the differences in the atmospheric and SAT anomalies related to the WP between the two epochs, as well as the factors responsible for the changes in WP variability.

During the high-variability epoch, a striking meridional atmospheric anomaly pattern occurred over the North Pacific, with significant anticyclonic anomalies over the western and central subtropical regions of the North Pacific and cyclonic anomalies over the Russian Far East and the Bering Strait. The atmospheric circulation anomalies during the low-variability epoch were much weaker and covered a smaller area than those recorded during the high-variability epoch (Fig. 14). Due to the stronger atmospheric anomalies, the WP had a more pronounced impact on the SAT anomalies over most parts of the Eurasian continent and North America during the high-variability epoch than during the low-variability epoch (Fig. 14).

During the high-variability epoch, a clear link was observed between ENSO and the WP (Fig. 14). In contrast, during the low-variability epoch, the ENSO-induced extratropical atmospheric circulation anomalies were closely aligned with those of the PNA pattern but had a weaker relation with the WP (Fig. 14). The stronger contribution of ENSO during the high-variability epoch partly contributed to the stronger variability in the winter WP. Further analysis suggested that the observed changes in the ENSOWP relationship were partly related to the zonal shift in ENSO-related SST anomalies over the tropical Pacific (Fig. 14). The SST anomalies in the tropical Pacific and ENSO-related extratropical North Pacific atmospheric anomalies were located farther westward during the high-variability epoch than during the 
low-variability epoch, causing a stronger projection on the WP and indicating a closer ENSO-WP connection (Fig. 14). The changes in the variability in the WP were also connected to changes in the intensity of the North Pacific storm track. The stronger intensity of the North Pacific storm track during the high-variability epoch led to stronger wave-mean flow interactions and stronger feedback of synopticscale eddies to the mean flow, also contributing to larger variability in the WP during this period (Fig. 14).

Previous studies have indicated that Eurasian snow cover and Arctic Sea ice anomalies (Kodera 1998; Linkin and Nigam 2008; Yuan et al. 2015; Oshika et al. 2014; Nakamura et al. 2015) also play roles in modulating the WP. Due to the limited length of available Eurasian snow cover data and the limited reliability of Arctic sea ice data before the satellite era, the roles of Eurasian snow cover and Arctic sea ice anomalies in modulating interdecadal changes in WP variability remain to be explored. In addition, the present analysis suggests that the zonal shift of SST anomalies in the tropical Pacific related to ENSO may partly contribute to changes in the ENSO-generated atmospheric circulation anomalies over the North Pacific and to changes in the ENSO-WP relation. However, this mechanism cannot fully explain the change in the spatial structure of the ENSO-induced extratropical atmospheric anomalies. The other factors that also contribute to changes in the ENSO-WP relation require further investigation.

\section{Declarations}

\section{Acknowledgments:}

This work was supported jointly by the National Natural Science Foundation of China (Grants 41961144025, 41975051 and 41721004), the Chinese Academy of Sciences Key Research Program of Frontier Sciences (QYZDY-SSW-DQC024), and the Jiangsu Collaborative Innovation Center for Climate Change.

Conflicts of interest/Competing interests: The authors declare no potential conflicts of interest.

Availability of data and material: NCEP-NCAR reanalysis data are derived from ftp://ftp.cdc.noaa.gov/Datasets/. JRA55 reanalysis data are derived from https://rda.ucar.edu/datasets/ds628.1/.ERA-Interim reanalysis data are derived from https://www.ecmwf.int/en/forecasts/datasets/reanalysis-datasets/era-interim. ERSSTV5 SST data are derived from https://www.esrl.noaa.gov/psd/data/gridded/. UDEL SAT data are derived from https://www.esrl.noaa.gov/psd/data/gridded/data.UDel_AirT_Precip.html.

Code availability (software application or custom code): Figures in this study are constructed with the NCAR Command Language (http://www.ncl.ucar.edu/). All codes used in this study are available from the corresponding author.

Authors' contributions: W.C. and S.F.C. designed the research, H. Aru performed the analysis. All authors wrote and revised the manuscript. 


\section{References}

1. Aru H, Chen S, Chen W (2021) Comparisons of the different definitions of the western Pacific pattern and associated winter climate anomalies in Eurasia and North America. Int J Climatol. https://doi.org/10.1002/joc.6993

2. Athanasiadis PJ, Wallace JM, Wettstein JJ (2010) Patterns of Wintertime Jet Stream Variability and Their Relation to the Storm Tracks*. J Atmos Sci 67:1361-1381. https://doi.org/10.1175/2009jas3270.1

3. Barnston AG, Livezey RE (1987) Classification, seasonality and persistence of low-frequency atmospheric circulation patterns. Monthly Weather Review 115:1083-1126. https://doi.org/10.1175/1520-0493(1987)115<1083:Csapol>2.0.Co;2

4. Barsugli JJ, Sardeshmukh PD (2002) Global atmospheric sensitivity to tropical SST anomalies throughout the Indo-Pacific basin. J Clim 15:3427-3442. https://doi.org/10.1175/15200442(2002)015<3427:Gastts>2.0.Co;2

5. Baxter S, Nigam S (2015) Key Role of the North Pacific Oscillation-West Pacific Pattern in Generating the Extreme 2013/14 North American Winter. J Clim 28:8109-8117. https://doi.org/10.1175/jcli-d-14-00726.1

6. Blackmon ML, Wallace JM, Lau N-C, Mullen SL (1977) An Observational Study of the Northern Hemisphere Wintertime Circulation. Journal of the Atmospheric Sciences 34:1040-1053. https://doi.org/10.1175/1520-0469(1977)034<1040:Aosotn>2.0.Co;2

7. Cai M, Yang S, Van Den Dool HM, Kousky VE (2007) Dynamical implications of the orientation of atmospheric eddies: a local energetics perspective. Tellus A: Dynamic Meteorology Oceanography 59:127-140. https://doi.org/10.1111/j.1600-0870.2006.00213.x

8. Chang EKM, Fu YF (2002) Interdecadal variations in Northern Hemisphere winter storm track intensity. J Clim 15:642-658. https://doi.org/10.1175/1520-0442(2002)015<0642:Ivinhw>2.0.Co;2

9. Chen S, Song L (2018) Impact of the Winter North Pacific Oscillation on the Surface Air Temperature over Eurasia and North America: Sensitivity to the Index Definition. Adv Atmos Sci 35:702-712. https://doi.org/10.1007/s00376-017-7111-5

10. Chen S, Wu R, Chen W, Hu K, Yu B (2020a) Structure and dynamics of a springtime atmospheric wave train over the North Atlantic and Eurasia. Clim Dyn 54:5111-5126. https://doi.org/10.1007/s00382020-05274-7

11. Chen S, Wu R, Chen W, Yu B (2020b) Recent weakening of the linkage between the spring Arctic Oscillation and the following winter El Niño-Southern Oscillation. Clim Dyn 54:53-67. https://doi.org/10.1007/s00382-019-04988-7

12. Chen S, Yu B, Chen W (2014) An analysis on the physical process of the influence of AO on ENSO. Clim Dyn 42:973-989. https://doi.org/10.1007/s00382-012-1654-z

13. Chen S, Yu B, Chen W (2015) An interdecadal change in the influence of the spring Arctic Oscillation on the subsequent ENSO around the early 1970s. Clim Dyn 44:1109-1126. 
https://doi.org/10.1007/s00382-014-2152-2

14. Chen S, Yu B, Wu R, Chen W, Song L (2021) The dominant North Pacific atmospheric circulation patterns and their relations to Pacific SSTs: historical simulations and future projections in the IPCC AR6 models. Clim Dyn 56:701-725. https://doi.org/10.1007/s00382-020-05501-1

15. Cheung HHN, Zhou W (2016) Simple metrics for representing East Asian winter monsoon variability: Urals blocking and western Pacific teleconnection patterns. Adv Atmos Sci 33:695-705. https://doi.org/10.1007/s00376-015-5204-6

16. Cheung HHN, Zhou W, Lee S-m, Tong H-w (2015) Interannual and Interdecadal Variability of the Number of Cold Days in Hong Kong and Their Relationship with Large-Scale Circulation. Mon Weather Rev 143:1438-1454. https://doi.org/10.1175/mwr-d-14-00335.1

17. Dai Y, Tan B (2019) Two Types of the Western Pacific Pattern, Their Climate Impacts, and the ENSO Modulations. J Clim 32:823-841. https://doi.org/10.1175/jcli-d-17-0618.1

18. Dee DP et al (2011) The ERA-Interim reanalysis: configuration and performance of the data assimilation system. Q J R Meteorol Soc 137:553-597. https://doi.org/10.1002/qj.828

19. Duchon CE (1979) LANCZOS FILTERING IN ONE AND 2 DIMENSIONS. J Appl Meteorol 18:10161022. https://doi.org/10.1175/1520-0450(1979)018<1016:Lfioat>2.0.Co;2

20. Frankignoul C, Sennéchael N, Kwon Y-O, Alexander MA (2011) Influence of the Meridional Shifts of the Kuroshio and the Oyashio Extensions on the Atmospheric Circulation. J Clim 24:762-777. https://doi.org/10.1175/2010jcli3731.1

21. Furtado JC, Di Lorenzo E, Anderson BT, Schneider N (2012) Linkages between the North Pacific Oscillation and central tropical Pacific SSTs at low frequencies. Clim Dyn 39:2833-2846. https://doi.org/10.1007/s00382-011-1245-4

22. He S, Wang H, Liu J (2013) Changes in the Relationship between ENSO and Asia-Pacific Midlatitude Winter Atmospheric Circulation. J Clim 26:3377-3393. https://doi.org/10.1175/jcli-d-12-00355.1

23. Hirose N, Nishimura K, Yamamoto M (2009) Observational evidence of a warm ocean current preceding a winter teleconnection pattern in the northwestern Pacific. Geophys Res Lett 36. https://doi.org/10.1029/2009gl037448

24. Hoerling MP, Kumar A (2002) Atmospheric response patterns associated with tropical forcing. J Clim 15:2184-2203. https://doi.org/10.1175/1520-0442(2002)015<2184:Arpawt>2.0.Co;2

25. Horel JD, Wallace JM (1981) Planetary-Scale Atmospheric Phenomena Associated with the Southern Oscillation. Monthly Weather Review 109:813-829. https://doi.org/10.1175/15200493(1981)109<0813:Psapaw>2.0.Co;2

26. Hsu HH, Wallace JM (1985) Vertical structure of wintertime teleconnection patterns. Journal of the Atmospheric Sciences 42:1693-1710. https://doi.org/10.1175/15200469(1985)042<1693:Vsowtp>2.0.Co;2

27. Hu P, Chen W, Chen SF, Liu YY, Wang L, Huang RP (2021) Impact of the March Arctic Oscillation on the South China Sea summer monsoon onset. Int J Climatol 41:E3239-E3248. https://doi.org/10.1002/joc.6920 
28. Huang BY et al (2017) Extended Reconstructed Sea Surface Temperature, Version 5 (ERSSTv5): Upgrades, Validations, and Intercomparisons. J Clim 30:8179-8205. https://doi.org/10.1175/jcli-d16-0836.1

29. Jin FF (2010) Eddy-Induced Instability for Low-Frequency Variability. J Atmos Sci 67:1947-1964. https://doi.org/10.1175/2009jas3185.1

30. Jin FF, Pan LL, Watanabe M (2006a) Dynamics of synoptic eddy and low-frequency flow interaction. Part I: A linear closure. J Atmos Sci 63:1677-1694. https://doi.org/10.1175/jas3715.1

31. Jin FF, Pan LL, Watanabe M (2006b) Dynamics of synoptic eddy and low-frequency flow interaction. Part II: A theory for low-frequency modes. J Atmos Sci 63:1695-1708. https://doi.org/10.1175/jas3716.1

32. Jo HS, Yeh SW, Lee SK (2015) Changes in the relationship in the SST variability between the tropical Pacific and the North Pacific across the 1998/1999 regime shift. Geophys Res Lett 42:7171-7178. https://doi.org/10.1002/2015gl065049

33. Kalnay E et al. (1996) The NCEP/NCAR 40-year reanalysis project. Bull Amer Meteorol Soc 77:437471. https://doi.org/10.1175/1520-0477(1996)077<0437:Tnyrp>2.0.Co;2

34. Kelley M et al (2020) GISS-E2.1: Configurations and Climatology. J Adv Model Earth Syst 12:e2019MS002025. https://doi.org/https://doi.org/10.1029/2019MS002025

35. Kobayashi S et al (2015) The JRA-55 Reanalysis: General Specifications and Basic Characteristics. J Meteorol Soc Jpn 93:5-48. https://doi.org/10.2151/jmsj.2015-001

36. Kodera K (1998) Consideration of the origin of the different midlatitude atmospheric responses among El Nino events. J Meteorol Soc Jpn 76:347-361. https://doi.org/10.2151/jmsj1965.76.3_347

37. Koide H, Kodera K (1999) A SVD analysis between the winter NH 500-hPa height and surface temperature fields. J Meteorol Soc Jpn 77:47-61. https://doi.org/10.2151/jmsj1965.77.1_47

38. Kug J-S, Jin F-F, Park J, Ren H-L, Kang I-S (2009) A general rule for synoptic-eddy feedback onto lowfrequency flow. Clim Dyn 35:1011-1026. https://doi.org/10.1007/s00382-009-0606-8

39. Lau NC (1988) Variability of the Observed Midlatitude Storm Tracks in Relation to Low-Frequency Changes in the Circulation Pattern. Journal of the Atmospheric Sciences 45:2718-2743. https://doi.org/Doi 10.1175/1520 - 0469(1988)045 < 2718:Votoms > 2.0.Co;2

40. Lau NC, Holopainen EO (1984) Transient Eddy Forcing of the Time-Mean Flow as Identified by Geopotential Tendencies. Journal of the Atmospheric Sciences 41:313-328. https://doi.org/Doi 10.1175/1520 - 0469(1984)041 < 0313:Tefott > 2.0.Co;2

41. Lau NC, Nath MJ (1991) Variability of the Baroclinic and Barotropic Transient Eddy Forcing Associated with Monthly Changes in the Midlatitude Storm Tracks. Journal of the Atmospheric Sciences 48:2589-2613. https://doi.org/10.1175/1520-0469(1991)048<2589:Votbab>2.0.Co;2

42. Lee $\mathrm{M}-\mathrm{Y}$, Hong $\mathrm{C}-\mathrm{C}$, Hsu H-H (2015) Compounding effects of warm sea surface temperature and reduced sea ice on the extreme circulation over the extratropical North Pacific and North America during the 2013-2014 boreal winter. Geophys Res Lett 42:1612-1618. https://doi.org/10.1002/2014gl062956 
43. Lee S-S et al (2012) Interdecadal changes in the storm track activity over the North Pacific and North Atlantic. Clim Dyn 39:313-327. https://doi.org/10.1007/s00382-011-1188-9

44. Li C, Wettstein JJ (2012) Thermally Driven and Eddy-Driven Jet Variability in Reanalysis. J Clim 25:1587-1596. https://doi.org/10.1175/jcli-d-11-00145.1

45. Lim Y-K, Kim H-D (2013) Impact of the dominant large-scale teleconnections on winter temperature variability over East Asia. Journal of Geophysical Research: Atmospheres 118:7835-7848. https://doi.org/10.1002/jgrd.50462

46. Linkin ME, Nigam S (2008) The North Pacific Oscillation-West Pacific Teleconnection Pattern: Mature-Phase Structure and Winter Impacts. J Clim 21:1979-1997. https://doi.org/10.1175/2007jcli2048.1

47. Ma X, Zhang Y (2018) Interannual variability of the North Pacific winter storm track and its relationship with extratropical atmospheric circulation. Clim Dyn 51:3685-3698. https://doi.org/10.1007/s00382-018-4104-8

48. Mo KC, Livezey RE (1986) Tropical-Extratropical Geopotential Height Teleconnections during the Northern Hemisphere Winter. Monthly Weather Review 114:2488-2515. https://doi.org/10.1175/1520-0493(1986)114<2488:Teghtd>2.0.Co;2

49. Nakamura H, Izumi T, Sampe T (2002) Interannual and decadal modulations recently observed in the Pacific storm track activity and East Asian winter monsoon. J Clim 15:1855-1874. https://doi.org/Doi 10.1175/1520 - 0442(2002)015 < 1855:ladmro > 2.0.Co;2

50. Nakamura H, Tanaka M, Wallace JM (1987) Horizontal Structure and Energetics of Northern Hemisphere Wintertime Teleconnection Patterns. Journal of the Atmospheric Sciences 44:33773391. https://doi.org/10.1175/1520-0469(1987)044<3377:Hsaeon>2.0.Co;2

51. Nakamura T, Hara M, Oshika M, Tachibana Y (2015) Impact of the winter North Atlantic Oscillation (NAO) on the Western Pacific (WP) pattern in the following winter through Arctic sea ice and ENSO. Part II: multi-model evaluation of the NAO-ENSO linkage. Clim Dyn 45:3547-3562. https://doi.org/10.1007/s00382-015-2556-7

52. Nishii K, Nakamura H, Orsolini YJ (2010) Cooling of the wintertime Arctic stratosphere induced by the western Pacific teleconnection pattern. Geophys Res Lett 37:n/a-n/a. https://doi.org/10.1029/2010gl043551

53. Oh H, Jhun J-G, Ha K-J, Seo K-H (2017) Combined effect of the East Atlantic/West Russia and Western Pacific teleconnections on the East Asian winter monsoon. Asia-Pac J Atmos Sci 53:273285. https://doi.org/10.1007/s13143-017-0030-7

54. Oshika M, Tachibana Y, Nakamura T (2014) Impact of the winter North Atlantic Oscillation (NAO) on the Western Pacific (WP) pattern in the following winter through Arctic sea ice and ENSO: part Iobservational evidence. Clim Dyn 45:1355-1366. https://doi.org/10.1007/s00382-014-2384-1

55. Park H-J, Ahn J-B (2016) Combined effect of the Arctic Oscillation and the Western Pacific pattern on East Asia winter temperature. Clim Dyn 46:3205-3221. https://doi.org/10.1007/s00382-015-2763-2 
56. Park YH, Kim BM, Pak G, Yamamoto M, Vivier F, Durand I (2018) A key process of the nonstationary relationship between ENSO and the Western Pacific teleconnection pattern. Sci Rep 8:9512. https://doi.org/10.1038/s41598-018-27906-z

57. Piao JL, Chen W, Chen SF, Gong HN, Chen XL, Liu B (2020) The intensified impact of El Nino on latesummer precipitation over East Asia since the early 1990s. Clim Dyn 54:4793-4809. https://doi.org/10.1007/s00382-020-05254-x

58. Rivière G (2010) Role of Rossby wave breaking in the west Pacific teleconnection. Geophys Res Lett 37:n/a-n/a. https://doi.org/10.1029/2010gl043309

59. Shi Z, Wang S (2019) Subseasonal Influences of Teleconnection Patterns on the Boreal Wintertime Surface Air Temperature over Southern China as Revealed from Three Reanalysis Datasets. Atmosphere 10. https://doi.org/10.3390/atmos10090514

60. Soulard N, Lin H, Yu B (2019) The changing relationship between ENSO and its extratropical response patterns. Sci Rep 9:6507. https://doi.org/10.1038/s41598-019-42922-3

61. Sung M-K, Jang H-Y, Kim B-M, Yeh S-W, Choi Y-S, Yoo C (2019) Tropical influence on the North Pacific Oscillation drives winter extremes in North America. Nature Climate Change 9:413-418. https://doi.org/10.1038/s41558-019-0461-5

62. Sung M-K, Yoo C, Yeh S-W, Kosaka Y, An S-I (2020) Characteristics of the North Pacific Oscillation in CMIP5 Models in Relation to Atmospheric Mean States. J Clim 33:3809-3825. https://doi.org/10.1175/jcli-d-19-0446.1

63. Takaya K, Nakamura H (2005a) Mechanisms of intraseasonal amplification of the cold Siberian high. J Atmos Sci 62:4423-4440. https://doi.org/10.1175/jas3629.1

64. Takaya K, Nakamura H (2005b) Geographical dependence of upper-level blocking formation associated with intraseasonal amplification of the Siberian high. J Atmos Sci 62:4441-4449. https://doi.org/Doi 10.1175/Jas3628.1

65. Takaya K, Nakamura H (2013) Interannual Variability of the East Asian Winter Monsoon and Related Modulations of the Planetary Waves. J Clim 26:9445-9461. https://doi.org/10.1175/jcli-d-1200842.1

66. Tanaka S, Nishii K, Nakamura H (2016) Vertical Structure and Energetics of the Western Pacific Teleconnection Pattern. J Clim 29:6597-6616. https://doi.org/10.1175/jcli-d-15-0549.1

67. Thompson DWJ, Wallace JM (2000) Annular modes in the extratropical circulation. Part I: Month-tomonth variability. J Clim 13:1000-1016. https://doi.org/10.1175/15200442(2000)013<1000:Amitec>2.0.Co;2

68. Trenberth KE, Branstator GW, Karoly D, Kumar A, Lau N-C, Ropelewski C (1998) Progress during TOGA in understanding and modeling global teleconnections associated with tropical sea surface temperatures. Journal of Geophysical Research: Oceans 103:14291-14324. https://doi.org/10.1029/97jc01444

69. Wallace JM, Gutzler DS (1981) Teleconnections in the geopotential height field during the Northern Hemisphere winter. Monthly Weather Review 109:784-812. https://doi.org/10.1175/1520- 
0493(1981)109<0784:Titghf>2.0.Co;2

70. Wang L, Chen W (2014) An Intensity Index for the East Asian Winter Monsoon. J Clim 27:2361-2374. https://doi.org/10.1175/jcli-d-13-00086.1

71. Wang L, Chen W, Huang R (2007) Changes in the variability of North Pacific Oscillation around 1975/1976 and its relationship with East Asian winter climate. J Geophys Res 112. https://doi.org/10.1029/2006jd008054

72. Wettstein JJ, Wallace JM (2010) Observed Patterns of Month-to-Month Storm-Track Variability and Their Relationship to the Background Flow*. J Atmos Sci 67:1420-1437. https://doi.org/10.1175/2009jas3194.1

73. Willmott CJ, Matsuura K (2001) Terrestrial Air Temperature and Precipitation: Monthly and Annual Time Series (1950-1999), http://climate.geog.udel.edu/ climate/html_pages/README.ghcn_ts2.html

74. Xu Z, Fan K (2020) Prolonged Periodicity and Eastward Shift of the January North Pacific Oscillation Since the Mid-1990s and Its Linkage With Sea Ice Anomalies in the Barents Sea. Journal of Geophysical Research: Atmospheres 125. https://doi.org/10.1029/2020jd032484

75. Yu B, Zhang X (2015) A physical analysis of the severe 2013/2014 cold winter in North America. Journal of Geophysical Research: Atmospheres 120. https://doi.org/10.1002/2015jd023116

76. Yuan J, Tan B, Feldstein SB, Lee S (2015) Wintertime North Pacific Teleconnection Patterns: Seasonal and Interannual Variability. J Clim 28:8247-8263. https://doi.org/10.1175/jcli-d-1400749.1

77. Zhao W, Chen SF, Chen W, Yao SL, Nath D, Yu B (2019) Interannual variations of the rainy season withdrawal of the monsoon transitional zone in China. Clim Dyn 53:2031-2046. https://doi.org/10.1007/s00382-019-04762-9

78. Zhao W, Chen W, Chen SF, Yao SL, Nath D (2020) Combined impact of tropical central-eastern Pacific and North Atlantic sea surface temperature on precipitation variation in monsoon transitional zone over China during August-September. Int J Climatol 40:1316-1327. https://doi.org/10.1002/joc.6231

79. Zhou Z-Q, Xie S-P, Zheng X-T, Liu Q, Wang H (2014) Global Warming-Induced Changes in El Niño Teleconnections over the North Pacific and North America. J Clim 27:9050-9064. https://doi.org/10.1175/jcli-d-14-00254.1

\section{Figures}




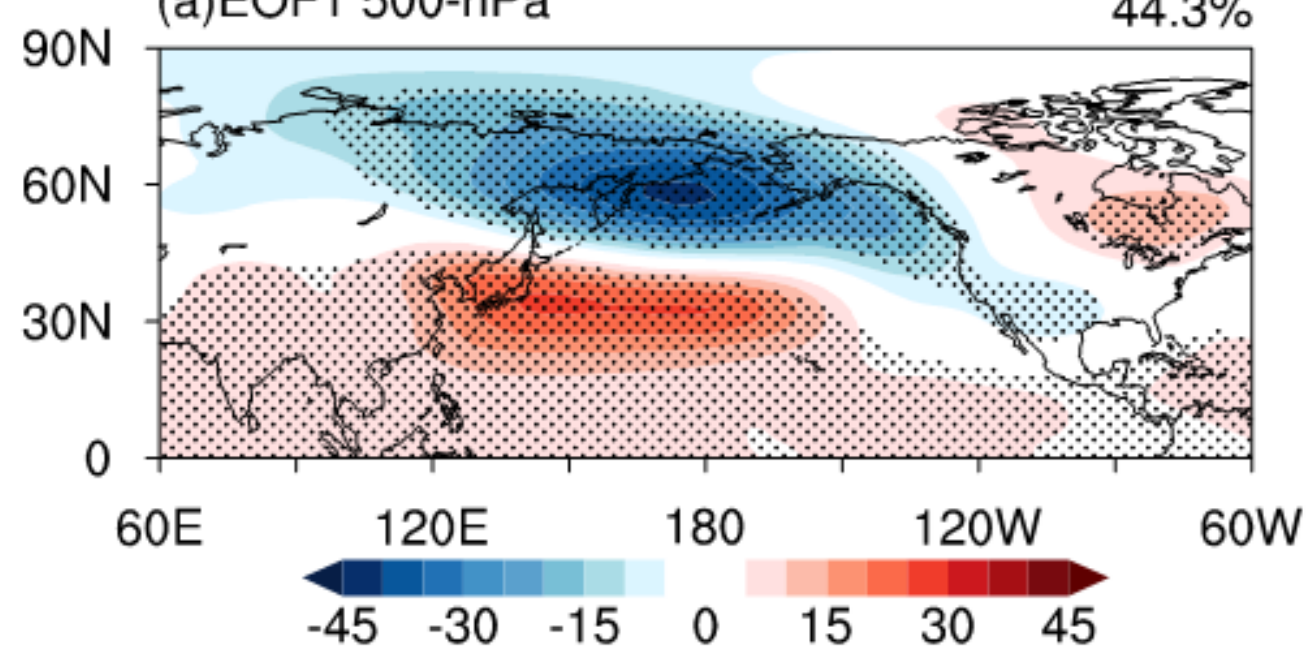

(b)DJF WPI

$1949-2019$

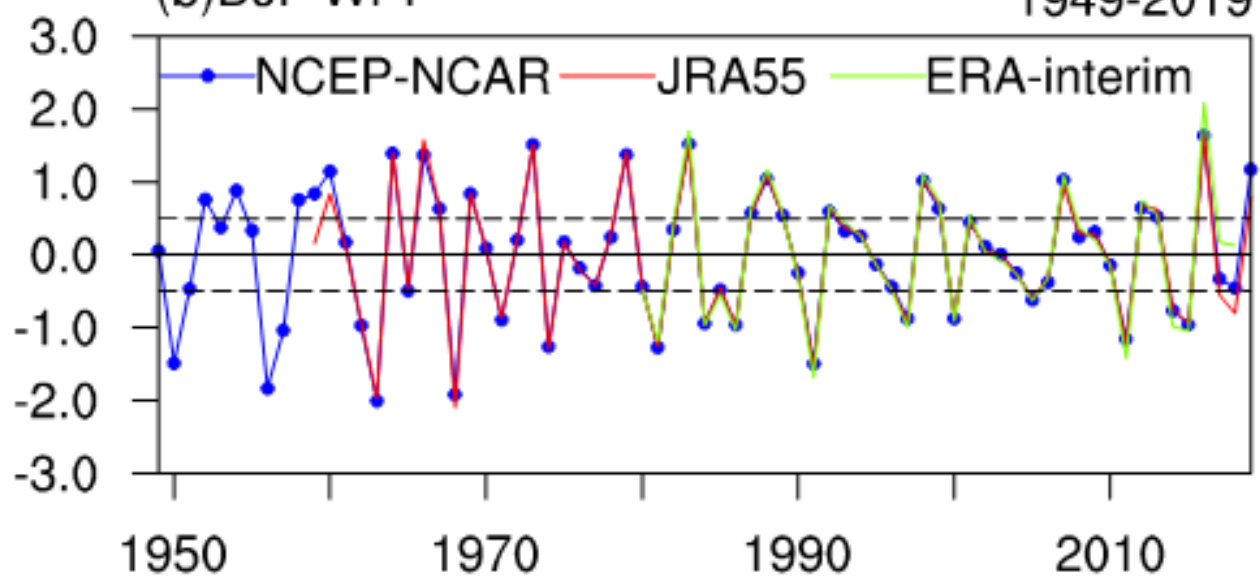

Figure 1

(a) Wintertime (DJF-mean) 500-hPa geopotential height anomalies obtained from the NCEP-NCAR dataset regressed upon the simultaneous winter WP index over 1949-2019. The winter WP index is defined as the PC1 time series of the $500-\mathrm{hPa}$ geopotential height anomalies over $20^{\circ} \mathrm{N}-70^{\circ} \mathrm{N}$ and $120^{\circ} \mathrm{E}-$ $180^{\circ}$. The stippling regions in (a) indicate anomalies that are significant at the $95 \%$ confidence level. (b) Time series of interannual variations in the winter WP index obtained from the NCEP-NCAR (blue line), JRA55 (red line), and ERA-Interim (green line) datasets. The years shown in (b) are labeled according to the January dates. The dashed horizontal lines in (b) represent 0.5 standard deviations of the WP index obtained from the NCEP-NCAR dataset. 
(a) WPI-25-yr-runSTD

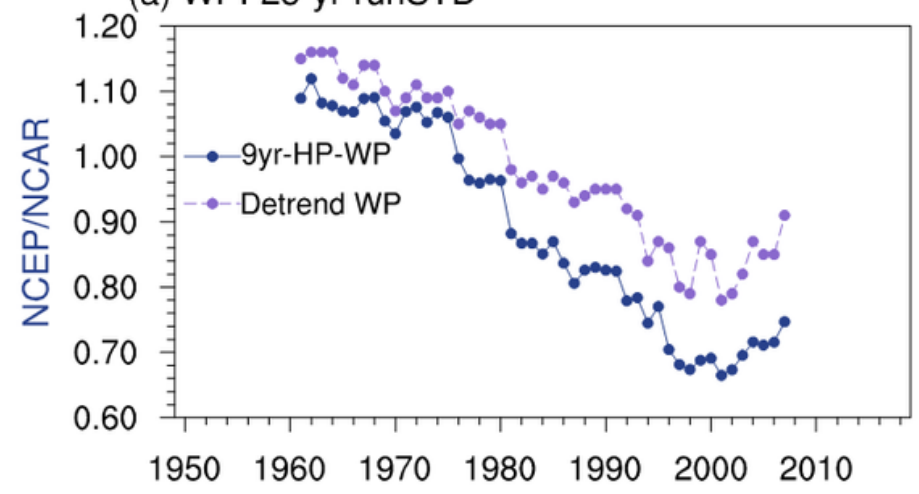

(b) WPI-25-yr-runSTD

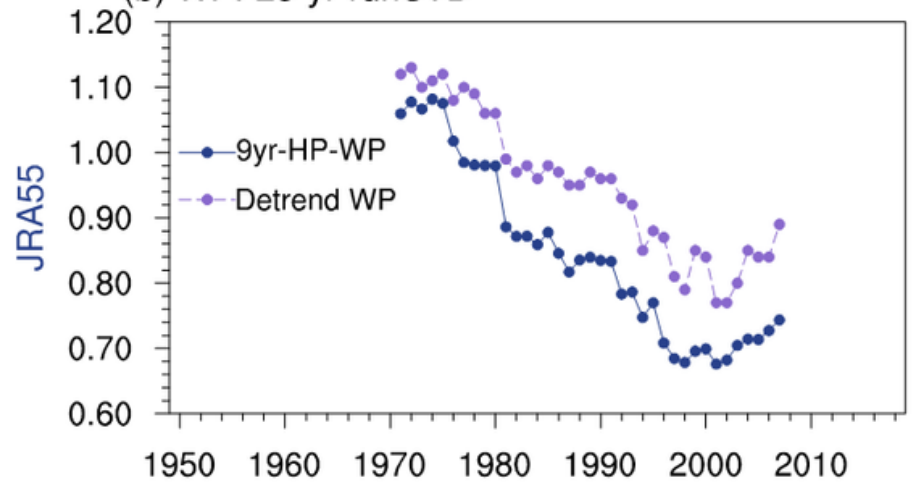

\section{Figure 2}

25-yr moving standard deviations of the 9-year high-pass filtered (blue dotted line) and detrended (purple dotted line) winter WP index from the (a) NCEP-NCAR dataset during 1949-2019 and (b) JRA55 dataset during 1959-2019. 
1950-1974

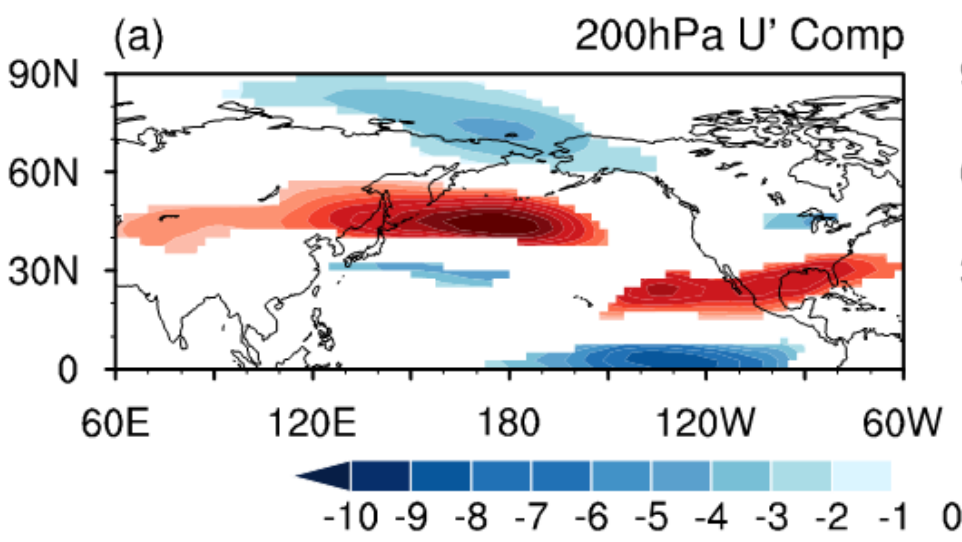

1989-2013

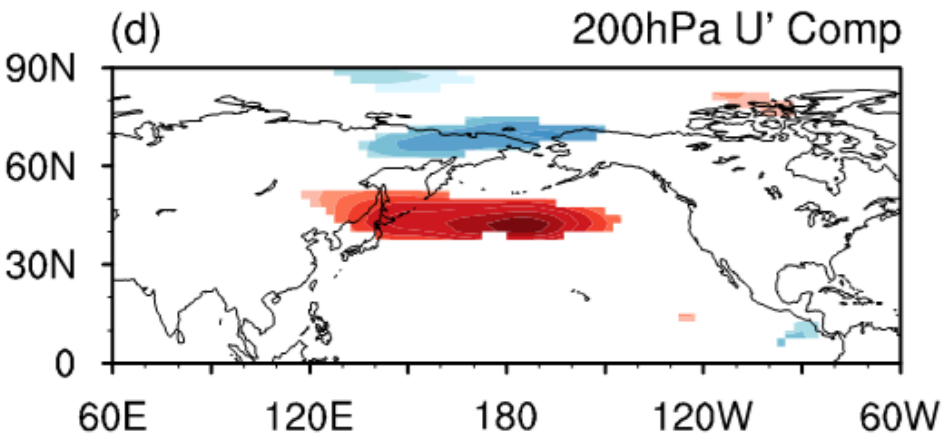

(b)

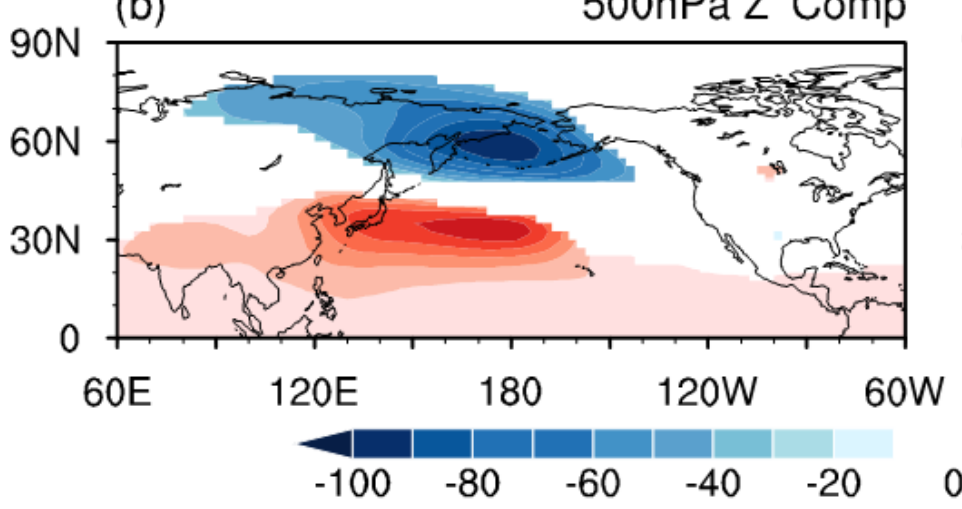

(e)

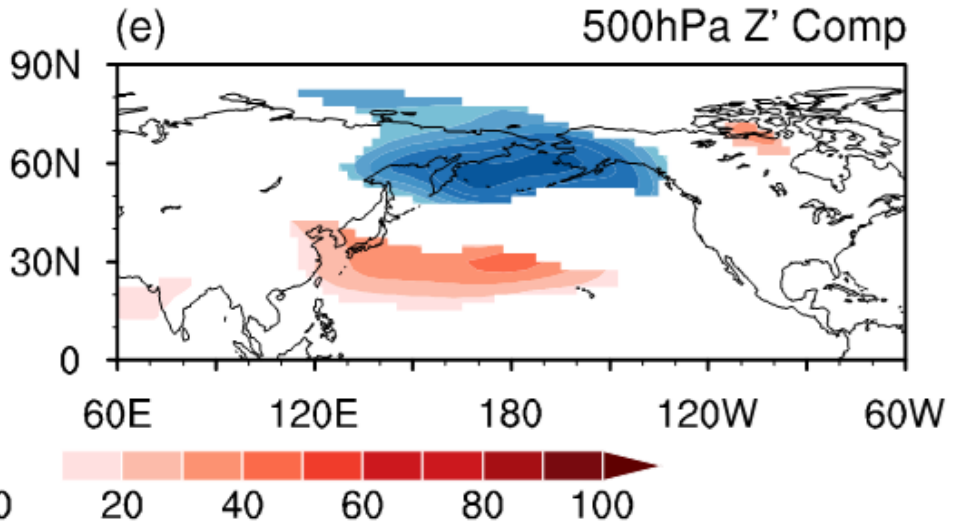

(c)

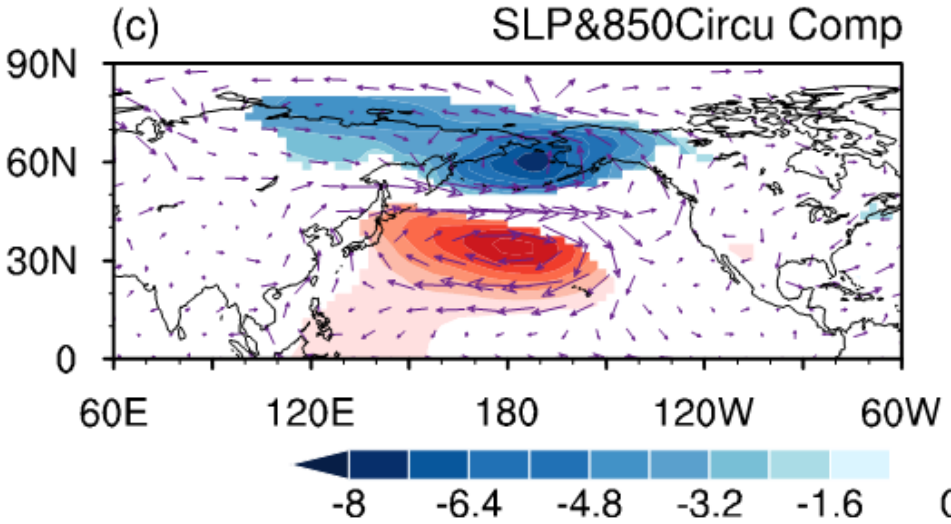

(f)

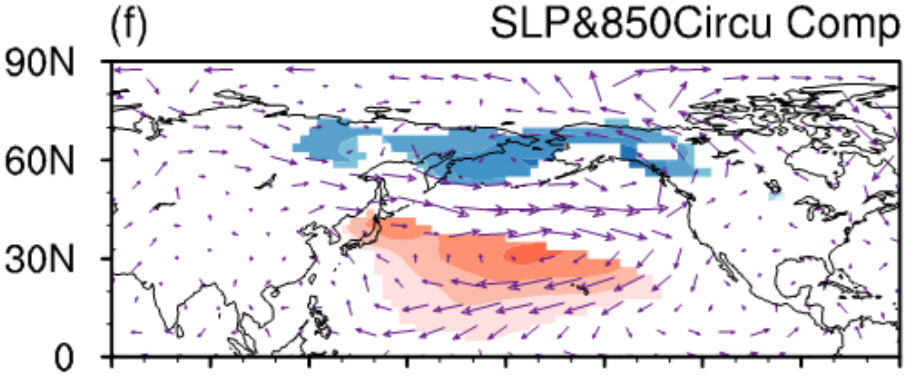

$\begin{array}{llllll}0 & 1.6 & 3.2 & 4.8 & 6.4 & 8\end{array}$

Figure 3

Composite differences in the winter 200-hPa zonal wind (unit: $\mathrm{m} \mathrm{s}-1$ ) between the positive and negative phases of the winter WP index during the (a) 1950-1974 and (d) 1989-2013 epochs. (b, e) As in (a, d) but for the 500-hPa geopotential height (unit: m). (c, f) As in (a, d) but for SLP (shading, unit: hPa) and 850$\mathrm{hPa}$ winds (vectors, unit: $\mathrm{m} \mathrm{s}-1$ ). The shaded anomalies are significant at the $95 \%$ confidence level. Wind anomalies less than $0.1 \mathrm{~m} \mathrm{~s}-1$ are not shown. 

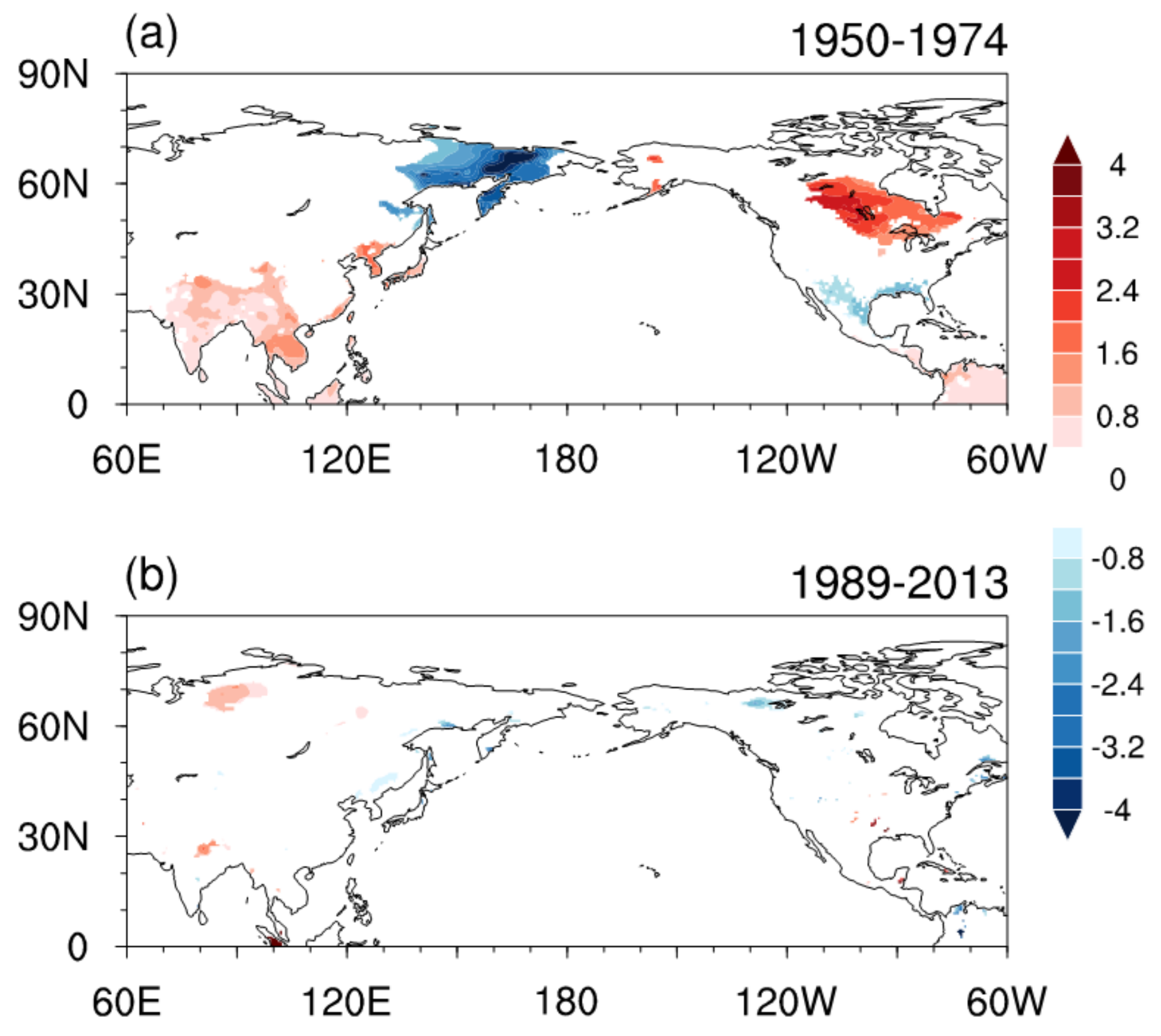

Figure 4

Composite differences in the winter surface air temperature (unit: ${ }^{\circ} \mathrm{C}$ ) between the positive and negative phases of the winter WP index during the (a) 1950-1974 and (b) 1989-2013 epochs. We only show the anomalies that are significant at the $95 \%$ confidence level. 


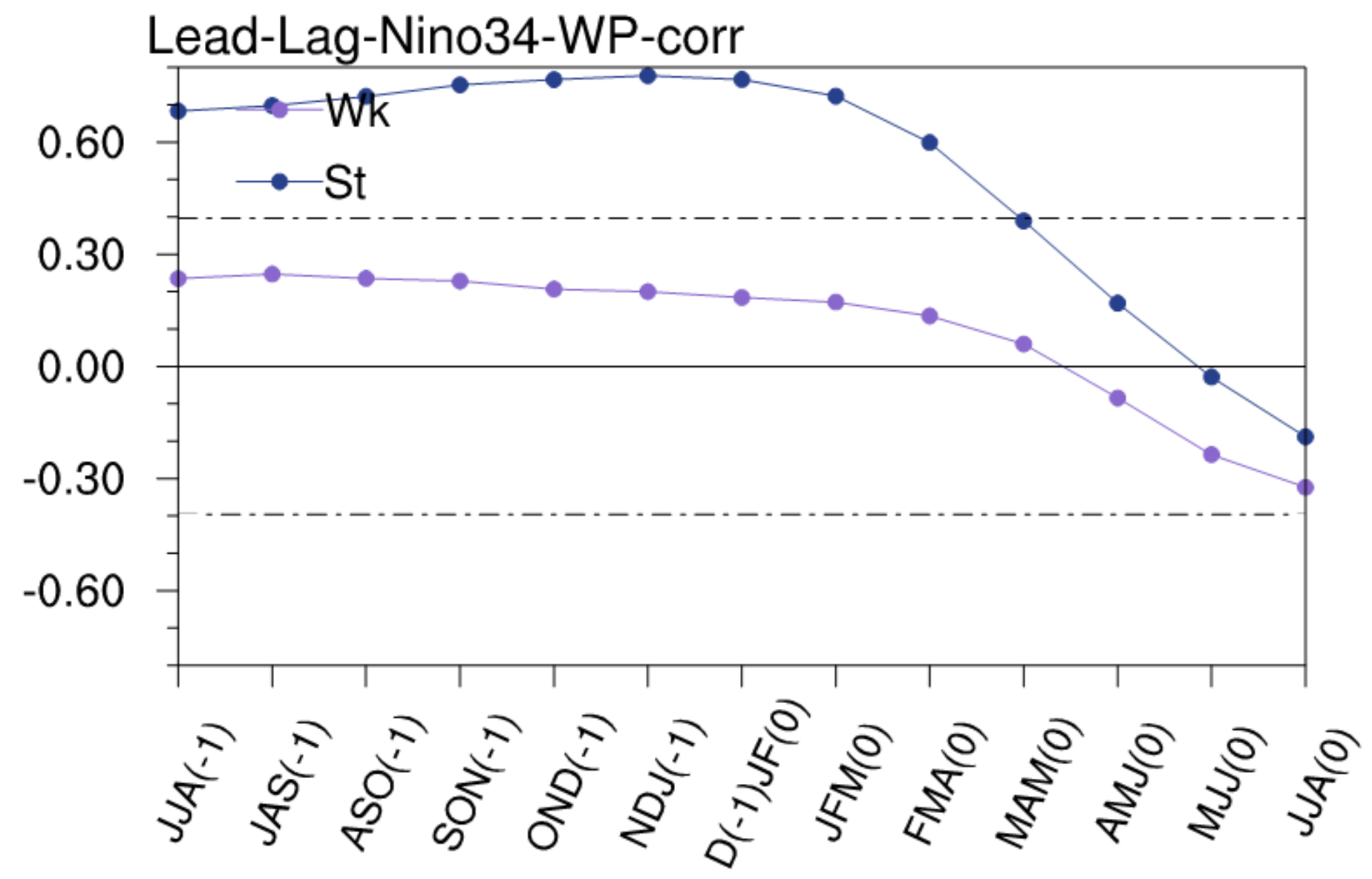

Figure 5

Lead-lag correlation coefficients between the winter WP index in the 1950-1974 (blue dotted line) and 1989-2013 (purple dotted line) epochs and the Niño3.4 index from the previous JJA (-1) to the following JJA (0). The dashed lines denote correlation coefficients that are significant at the $95 \%$ confidence level.

(a)

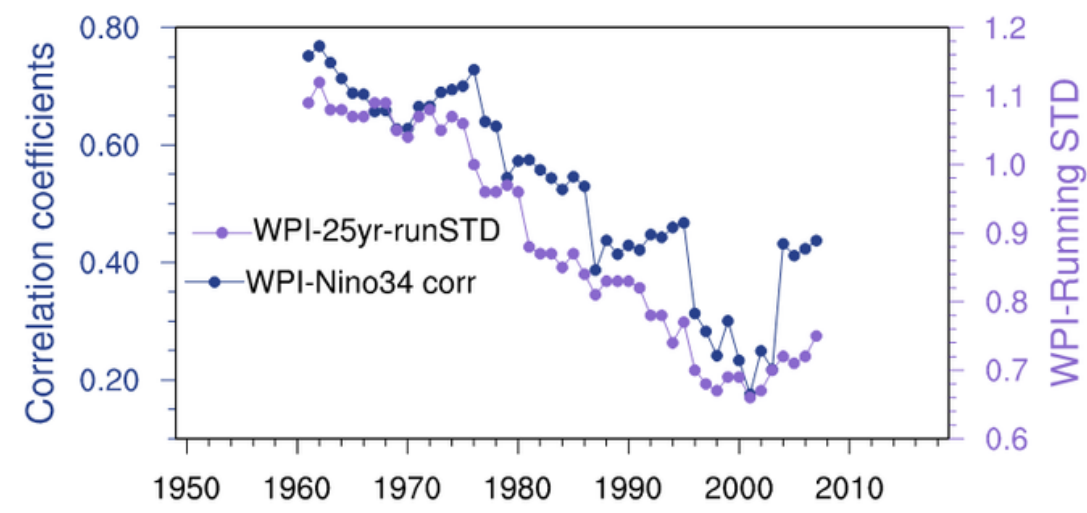

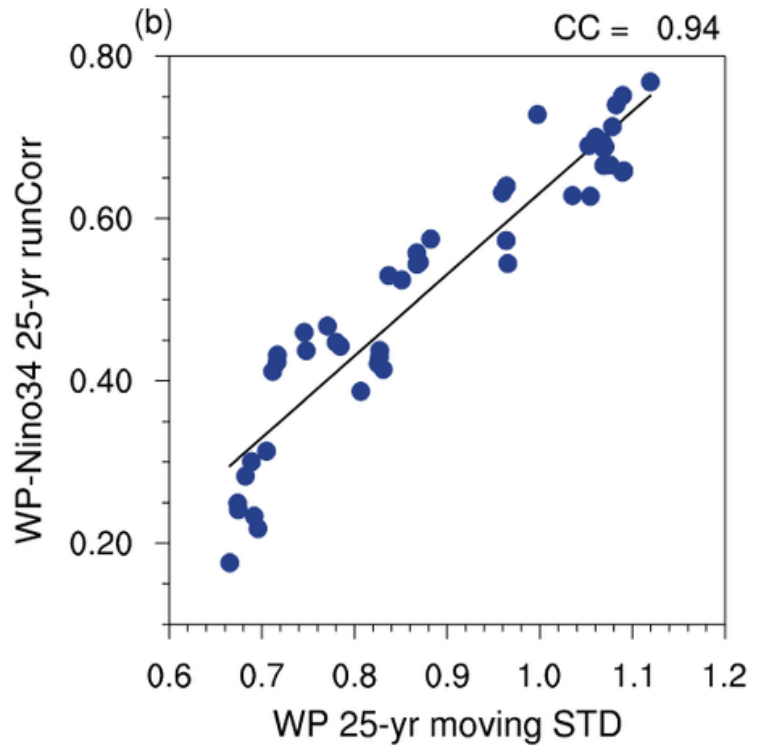

Figure 6 
(a) The 25-yr running correlation coefficients (blue line) of the winter WP index and Niño3.4 index (blue dotted line) and the 25-yr running standard deviations (purple line) of the winter WP index displayed in the central year of a 25-yr window. (b) Scatter plot of the 25-yr running correlations of winter WP index and Niño3.4 index against the 25-yr running standard deviations of the winter WP index.

\section{0-1974}

(a)

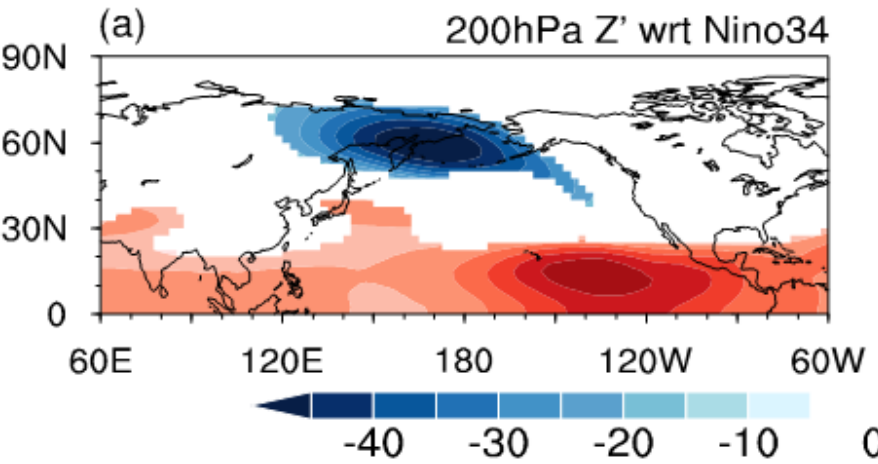

(b)

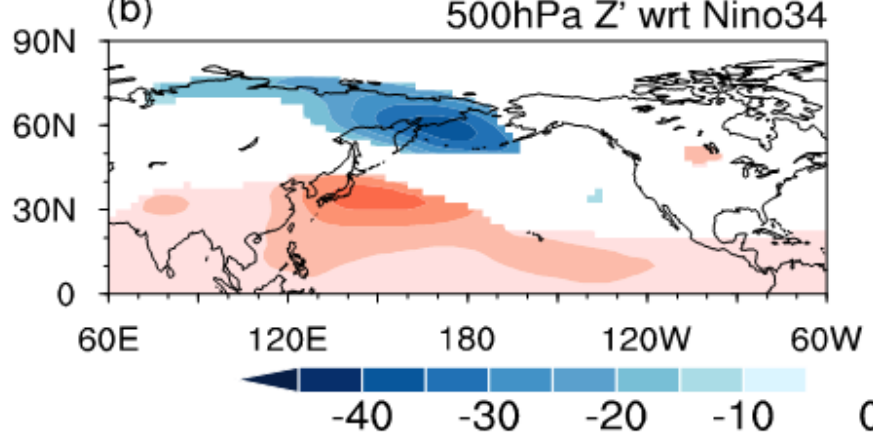

1989-2013

(e)

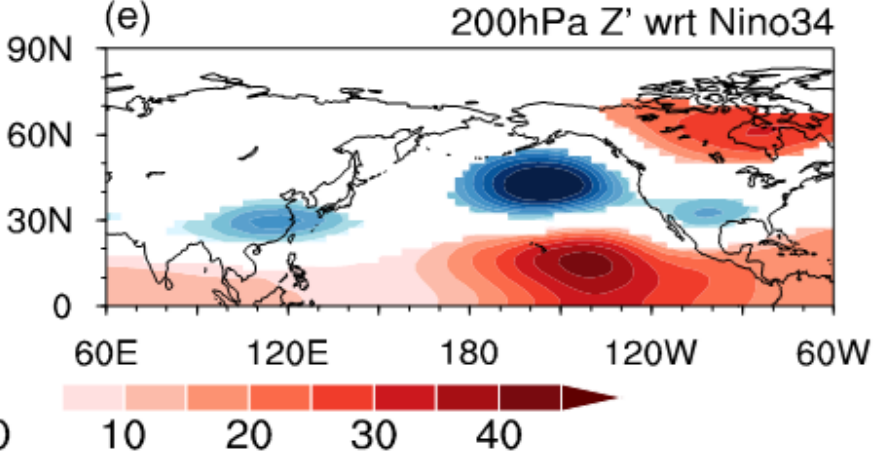

(c) SLP\&850Circu wrt Nino34
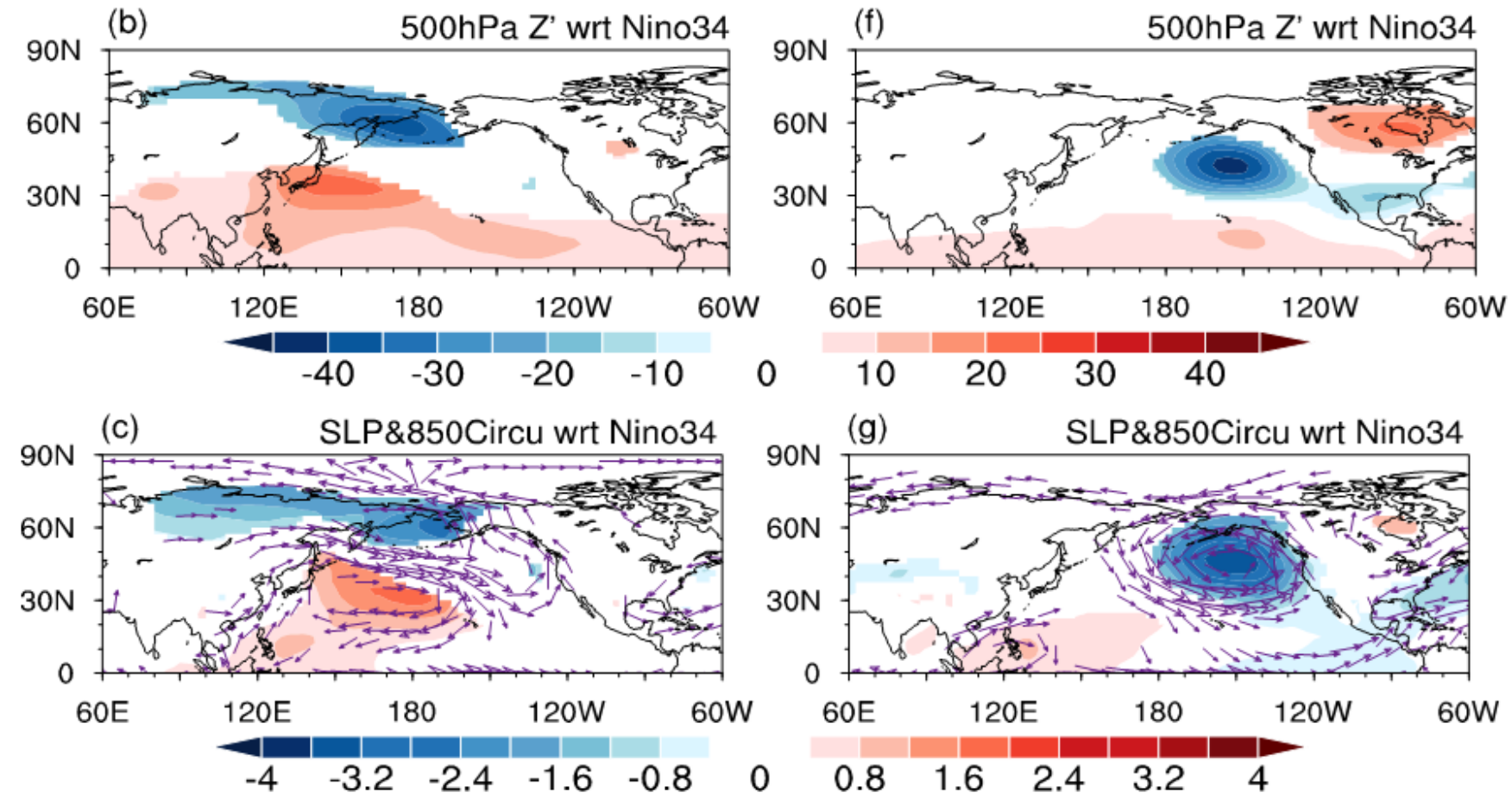

(d)

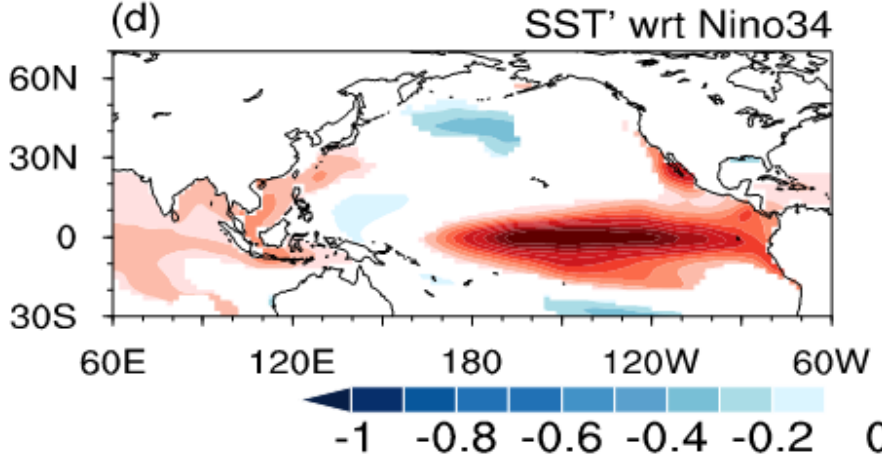

(h)
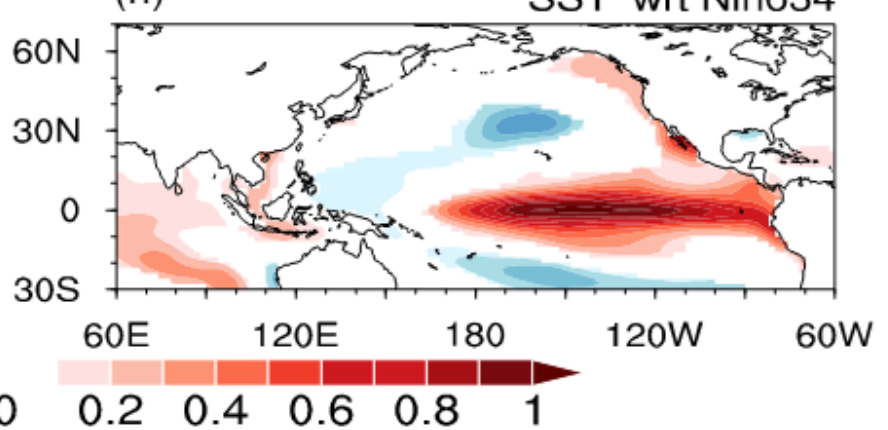

Figure 7 
Regression patterns of the winter (a) 200-hPa geopotential height (m), (b) 500-hPa geopotential height (m), (c) SLP (shadings, hPa) and 850-hPa winds (vectors, $\mathrm{m} \mathrm{s}-1$ ), and (d) SST $\left({ }^{\circ} \mathrm{C}\right.$ ) anomalies onto the simultaneous winter Niño3.4 index during 1950-1974. (e-h) As in (a-d) but for 1989-2013. The shaded regions indicate anomalies that are significant at the $95 \%$ confidence level. Wind anomalies less than 0.5 $\mathrm{m} \mathrm{s}-1$ in both directions are not shown.
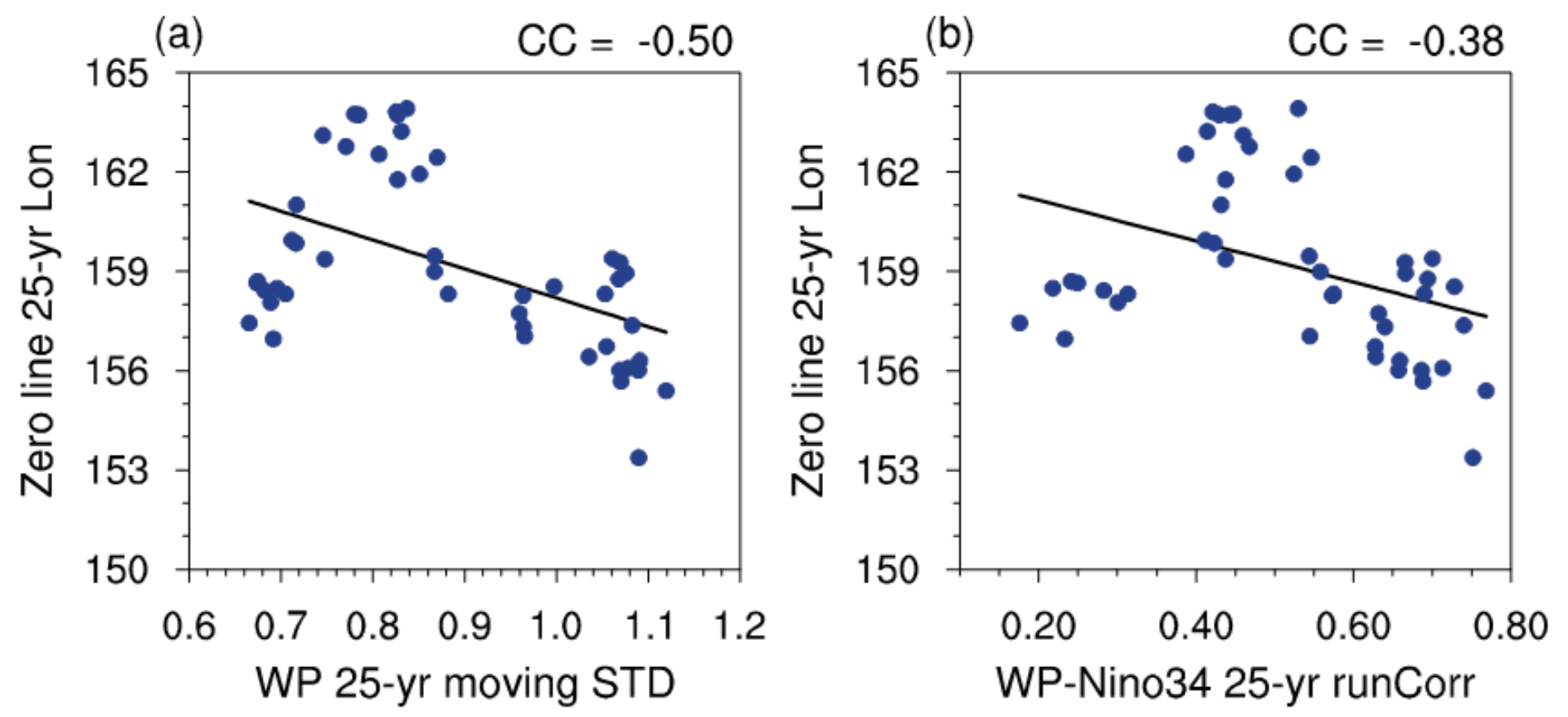

Figure 8

Scatter plot of the zero line longitude of winter SST anomalies related to the winter Niño3.4 index over the tropical $\left(5^{\circ} \mathrm{S}-5^{\circ} \mathrm{N}\right.$ average) western-central Pacific versus (a) the standard deviation of the winter WP index with a 25-yr moving window and (b) the correlation coefficients between the winter WP and Niño3.4 indices with a 25-yr moving window.
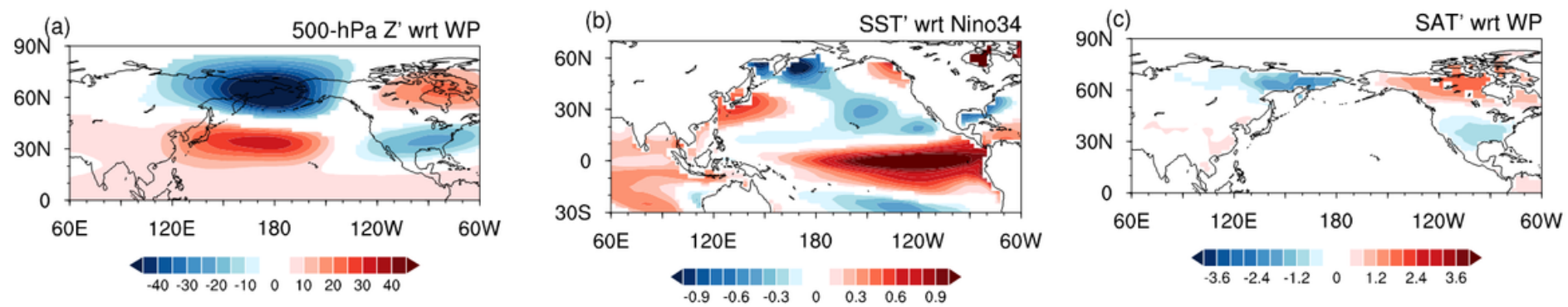

\section{Figure 9}

Regression patterns of the winter (a) 500-hPa geopotential height $(\mathrm{m})$ and (c) surface air temperature anomalies $\left({ }^{\circ} \mathrm{C}\right)$ onto the normalized winter WP index from the historical simulation of the GISS-E2-1-G model over 1850-2014. (b) Regression pattern of winter sea surface temperature anomalies $\left({ }^{\circ} \mathrm{C}\right)$ with respect to the normalized winter Niño3.4 index from the historical simulation of the GISS-E2-1-G model over 1850-2014. Anomalies that are significant at the 95\% confidence level are shaded. 
(a)
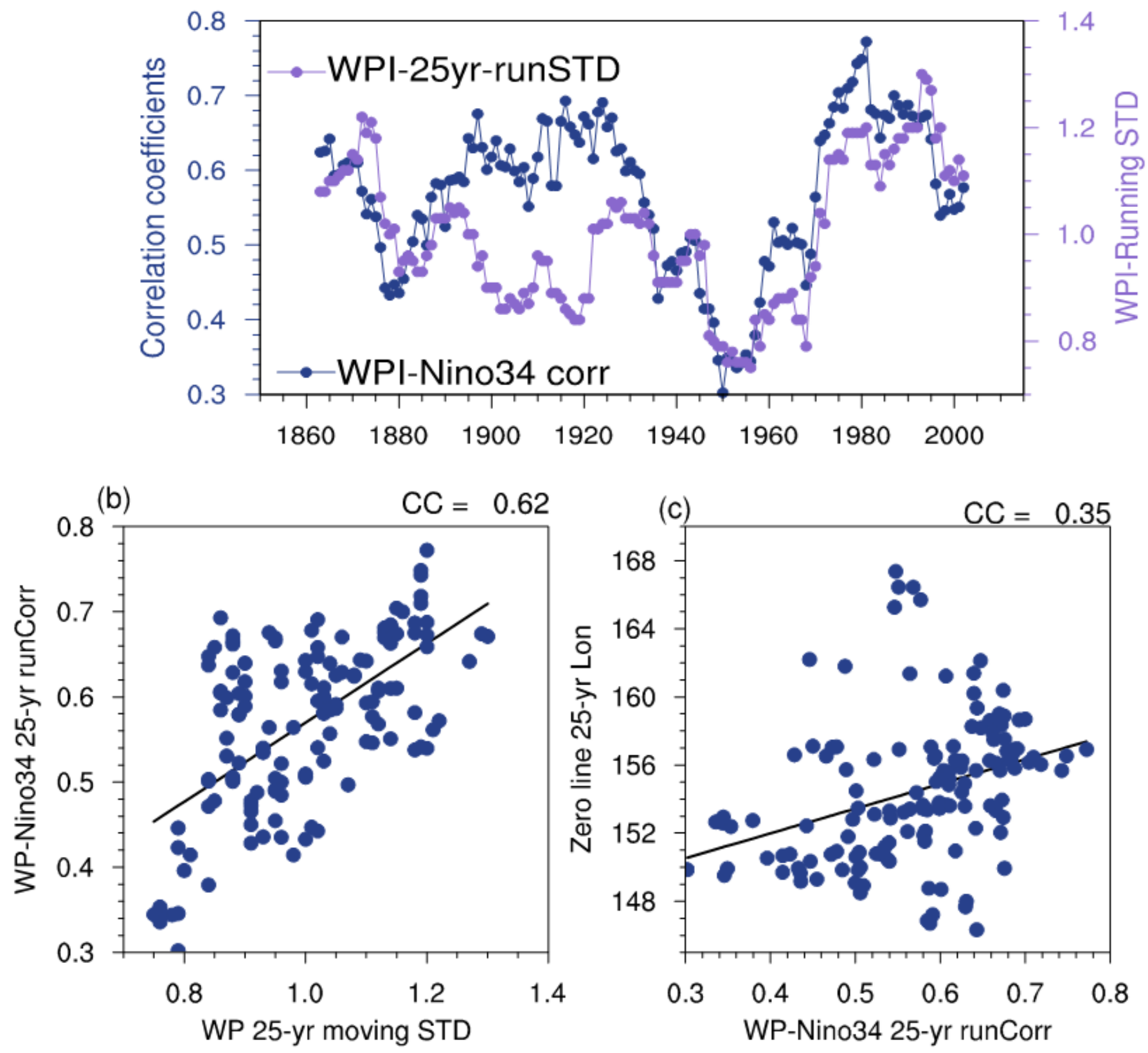

Figure 10

(a) The 25-yr running correlations (blue line) of the winter WP index with the Niño3.4 index and the 25-yr running standard deviations (red line) of the winter WP index obtained from the historical simulations of the GISS-E2-1-G model over 1850-2014. (b) Scatter plot of the 25-yr moving standard deviations of the winter WP index versus the 25-yr running correlations of the winter WP index with the Niño3.4 index. (c) Scatter plot of the 25-yr running correlations of the winter WP index with the Niño3.4 index versus the zero line longitude of winter SST anomalies related to the winter Niño3.4 index over the tropical $\left(5^{\circ} \mathrm{S}-5^{\circ} \mathrm{N}\right.$ average) western-central Pacific from the historical simulations of the GISS-E2-1-G model over 18502014. 

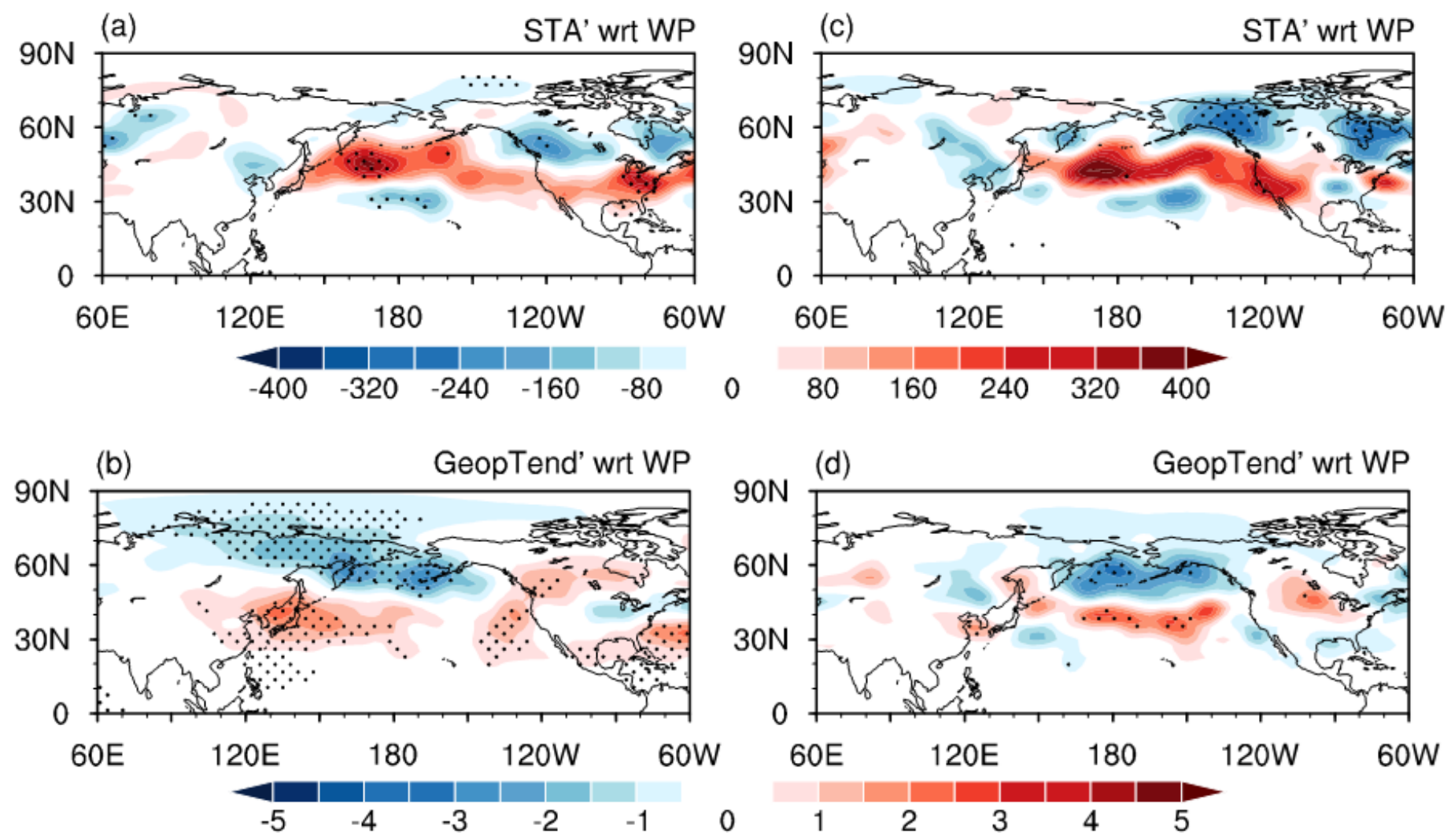

\section{Figure 11}

Regression patterns of the winter (a) storm track (unit: $\mathrm{m} 2$ ) and (b) geopotential height tendency (unit: $\mathrm{m}$ day-1) anomalies at $500 \mathrm{hPa}$ onto the normalized winter WP index during 1950-1974. (c) and (d) As in (a) and (b) but for 1989-2013. The stippled regions indicate anomalies that are significant at the $95 \%$ confidence level. 

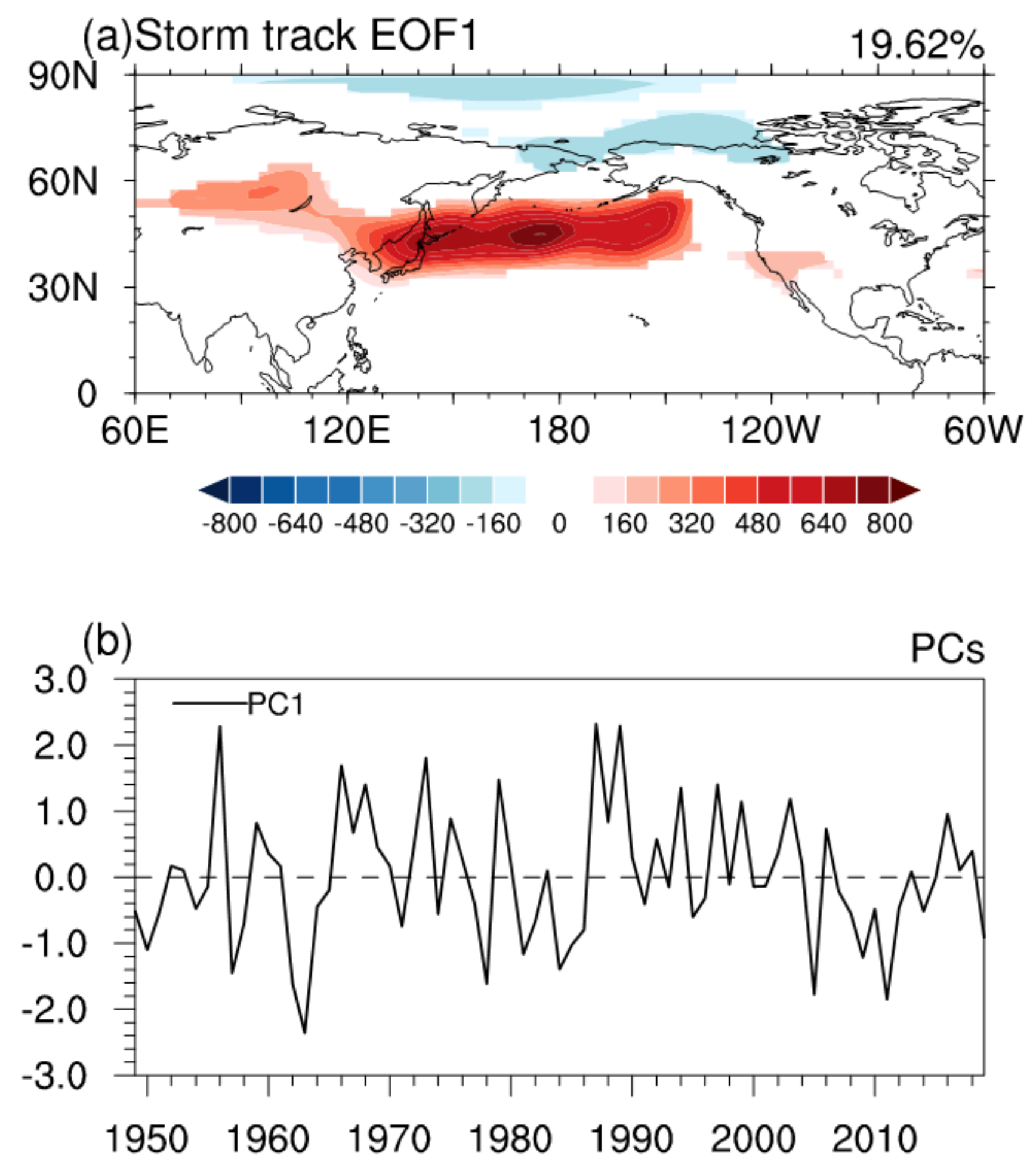

Figure 12

(a) Winter storm track anomalies (unit: $\mathrm{m} 2$ ) regressed upon the PC time series corresponding to the EOF1 of winter storm track anomalies over the North Pacific $\left(20^{\circ}-90^{\circ} \mathrm{N}, 120^{\circ} \mathrm{E}-100^{\circ} \mathrm{W}\right)$ during $1949-2019$. The shaded regions indicate storm track anomalies that are significant at the $95 \%$ confidence level. (b) The PC time series of the EOF1 of winter storm track activity over the North Pacific for 1949-2019. 


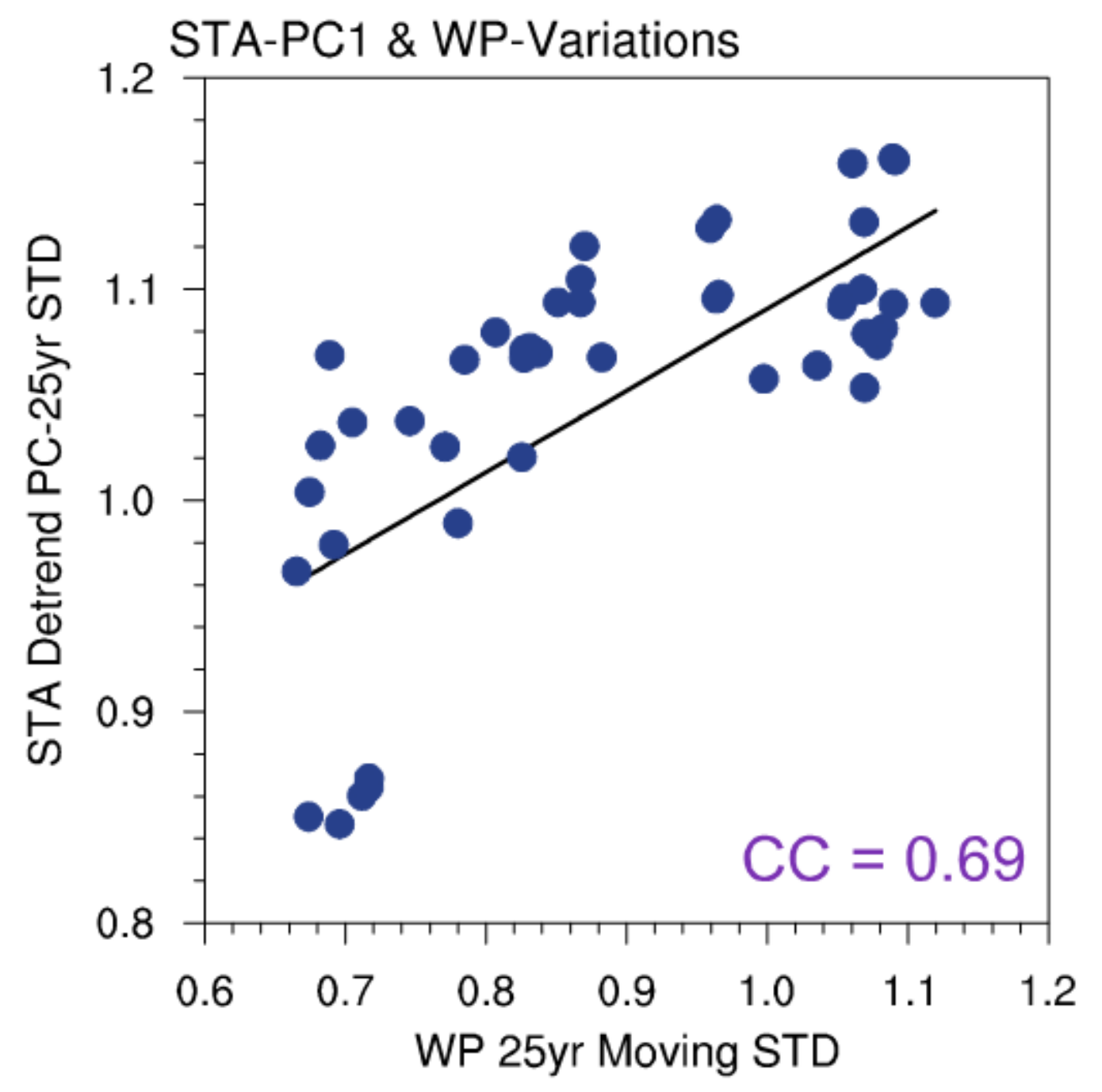

Figure 13

Scatterplot of the 25-yr moving standard deviations of the winter WP index versus the 25-yr running standard deviations of the North Pacific storm track intensity. The black line denotes the linear fit between the two variables. 


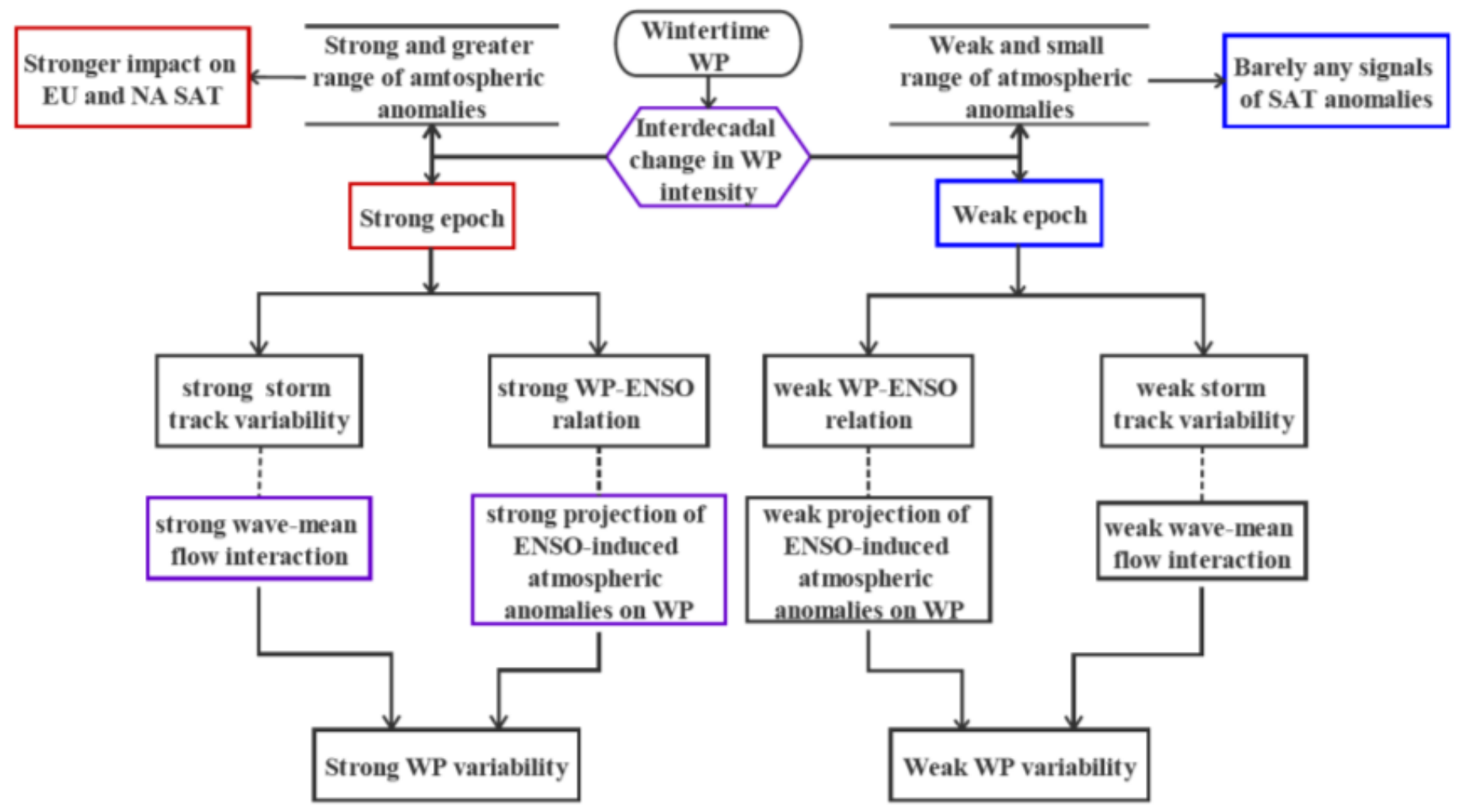

Figure 14

Schematic diagram illustrating the factors responsible for the interdecadal changes in WP variability. 